\title{
Water addition regulates the metabolic activity of ammonia oxidizers responding to environmental perturbations in dry subhumid ecosystems
}

\author{
Hang-Wei Hu, ${ }^{1,2}$ Catriona A. Macdonald, ${ }^{1}$ \\ Pankaj Trivedi, ${ }^{1}$ Bronwyn Holmes, ${ }^{3}$ \\ Levente Bodrossy, ${ }^{3} \mathrm{Ji}$-Zheng $\mathrm{He}^{2 * \star}$ and \\ Brajesh K. Singh ${ }^{1 *}$ \\ ${ }^{1}$ Hawkesbury Institute for the Environment, University of \\ Western Sydney, Penrith South DC, NSW 2751, \\ Australia. \\ ${ }^{2}$ State Key Laboratory of Urban and Regional Ecology, \\ Research Center for Eco-Environmental Sciences, \\ Chinese Academy of Sciences, Beijing 100085, China. \\ ${ }^{3}$ Marine and Atmospheric Research and Wealth from \\ Oceans National Research Flagship, CSIRO, Hobart, \\ Tas., Australia.
}

\section{Summary}

Terrestrial arid and semi-arid ecosystems (drylands) constitute about $41 \%$ of the Earth's land surface and are predicted to experience increasing fluctuations in water and nitrogen availability. Mounting evidence has confirmed the significant importance of ammonia-oxidizing archaea (AOA) and bacteria (AOB) in nitrification, plant nitrogen availability and atmospheric $\mathrm{N}_{2} \mathrm{O}$ emissions, but their responses to environmental perturbations in drylands remain largely unknown. Here we evaluate how the factorial combinations of irrigation and fertilization in forests and land-use change from grassland to forest affects the dynamics of $A O A$ and $A O B$ following a 6-year dryland field study. Potential nitrification rates and $A O A$ and $A O B$ abundances were significantly higher in the irrigated plots, accompanied by considerable changes in community compositions, but their responses to fertilization alone were not significant. DNA-stable isotope probing results showed increased ${ }^{13} \mathrm{CO}_{2}$ incorporation into the amoA gene of AOA, but not of $A O B$, in plots receiving water addition, coupled with significantly higher net mineralization and nitrification rates. High-throughput microarray analysis

Received 12 January, 2014; accepted 4 April, 2014. For correspondence. $\quad{ }^{*} E-m a i l \quad b . s i n g h @ u w s . e d u . a u ; \quad T e l . \quad(+61) 2$ 45701392;

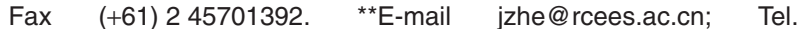
(+86) 10 62849788; Fax (+86) 1062923563. revealed that active $A O A$ assemblages belonging to Nitrosopumilus and Nitrosotalea were increasingly labelled by ${ }^{13} \mathrm{CO}_{2}$ following irrigation. However, no obvious effects of land-use changes on nitrification rates or metabolic activity of $A O A$ and $\triangle O B$ could be observed under dry conditions. We provide evidence that water addition had more important roles than nitrogen fertilization in influencing the autotrophic nitrification in dryland ecosystems, and AOA are increasingly involved in ammonia oxidation when dry soils become wetted.

\section{Introduction}

Arid and semi-arid ecosystems (drylands) are extensively distributed around the world and occupy c. $41 \%$ of the Earth's land surface, representing the largest terrestrial biome on the planet (Schimel, 2010). The total area of drylands is predicted to expand continuously in many regions (Dai, 2013), which could greatly affect ecosystem functioning and plant nutrition by exerting differential controls on the biogeochemical nutrient cycling processes (Delgado-Baquerizo et al., 2013). Simultaneously, terrestrial ecosystems are increasingly influenced by intensive anthropogenic perturbations and climatic changes (Houghton et al., 2001; Singh et al., 2010), which might have profound consequences on belowground nutrient allocation and lead to increased fluctuations in precipitation magnitude and frequency at regional and continental levels (Dore, 2005). Impacts of environmental changes on nutrients cycling, however, are particularly relevant within drylands because these ecosystems are highly vulnerable and characterized by extremely low availability of water and nutrients (Delgado-Baquerizo et al., 2013). Despite the global expense of drylands and significant importance of nutrient cycling in ecosystem services and primary production, it is largely unknown how these cycles are maintained by soil microorganisms, and limited studies have been conducted to provide microbial explanations for their responses to land perturbations in these ecosystems.

Nitrification, as an essential component of the global nitrogen cycle, is a microbially regulated process converting ammonia to nitrate via nitrite and leads to change in plant nitrogen availability, nitrate leaching into groundwater 
and atmospheric emissions of greenhouse gas $\mathrm{N}_{2} \mathrm{O}$ (Wrage et al., 2001; Singh et al., 2010). The first step involving conversion of ammonia to nitrite is often assumed to be rate limiting and performed by two distinct groups of prokaryotes: ammonia-oxidizing bacteria $(\mathrm{AOB})$ affiliated within the $\beta$ - or $\gamma$-Proteobacteria (Purkhold et al., 2000), and recently discovered ammonia-oxidizing archaea (AOA) within the Thaumarchaeota phylum (BrochierArmanet et al., 2008). Numerous studies have attempted to decipher the distinct ecological niches of $A O A$ and $A O B$, and their relative contributions to autotrophic nitrification (Prosser and Nicol, 2012). These findings demonstrated potential niche differentiations between $\mathrm{AOA}$ and $\mathrm{AOB}$ shaped by multiple environmental and climatic factors (Erguder et al., 2009; Yao et al., 2013) and a distinct pathway of $A O A$ ammonia oxidation from that of $A O B$ (Walker et al., 2010). AOA are now known to be remarkably abundant and frequently outnumber their counterpart $A O B$ in various terrestrial environments (Hu et al., 2013; Yao et al., 2013). However, numerical dominance is often not equivalent to functional importance, for instance, soils numerically occupied by AOA might be functionally dominated by AOB (Shen et al., 2008; Jia and Conrad, 2009; Xia et al., 2011), and most assessments of microbial communities generally included populations not actively contributing to ecosystem functioning (Lennon and Jones, 2011). Hence, the ecologically functional patterns of AOA and $A O B$ and their relative contributions to nitrification affected by different environmental factors are often hard to discern.

There have been a large body of studies addressing how environmental disturbances altered soil nitrifying communities; most of the literature, however, is dominated by the ecosystems where water is not limited ( $\mathrm{He}$ et al., 2007; Shen et al., 2008; Erguder et al., 2009). Responses of ammonia oxidizers in arid and semi-arid ecosystems, particularly in dryland forests, are largely less documented. Eucalyptus plantations are widely spread across many global areas, and fertilization and irrigation are increasingly employed to accelerate wood production and shorten rotation times by alleviating nutritional and water deficiencies (Myers et al., 1996). Substantial evidence has suggested the great importance of water and nitrogen availability in impacting the net primary production and biological activity in dryland forest ecosystems (Austin et al., 2004; Delgado-Baquerizo et al., 2013). Nevertheless, few studies have investigated the effects of irrigation and fertilization on ammonia oxidizers (Chen et al., 2013), and we still lack a mechanistic understanding of how irrigation and fertilization interact to regulate the fate of nitrogen, hence the nutrient availability for plants in dryland forest soils.

The major goal of this study was to elucidate how the abundance, community composition and metabolic capacity of ammonia oxidizers changed in a Eucalyptus forest soil within a dryland ecosystem subjected to fertilization and irrigation regimes for 6 years. We also examined the impact of land-use change from grassland to forest on these parameters. Soils taken from the field were subsequently tested in a 30 day ${ }^{13} \mathrm{CO}_{2}$-DNA-stable isotope probing microcosm, which allowed deciphering the metabolically active players involved in ammonia oxidation (Zhang et al., 2012). A functional gene array (Abell et al., 2012) with excellent capacity of detecting amoA genes was employed to disentangle the detailed changes in ammonia-oxidizing community structures. We hypothesized that: (i) nitrogen fertilization and water addition could favour the nitrogen mineralization and nitrification activity in drylands, but availability of water would have more dominant effects than fertilization, because dryland soils are mainly characterized by low water contents and (ii) metabolic activity of $A O A$ and $A O B$ might respond differently to nitrogen and water addition, owing to their divergent ecological niches and ammonia substrate affinity.

\section{Results}

Variations of soil characteristics across different treatments

Inorganic nitrogen, soil $\mathrm{pH}$ and moisture contents were greatly affected by 6 years of land-management and landuse practices (Fig. 1). Afforestation of grassland with Eucalyptus trees resulted in a significant decrease in soil $\mathrm{pH}$ from 6.05 to 5.20 , and soil $\mathrm{pH}$ was further decreased to 4.62 in winter samples of the fertilization $(F)$ treatment. The irrigation (I) and irrigation + fertilization (IF) treatments had considerably higher $\mathrm{pH}$ values around neutral and, as expected, significantly enhanced soil moisture contents ranging from $5.92 \%$ to $8.60 \%$. Soil moisture contents in other three treatments were remarkably limited (around $2 \%$ ), with a slightly higher value $(4.77 \%$ ) recorded in the winter grassland $(\mathrm{G})$ soils. The $\mathrm{NH}_{4}{ }^{+}-\mathrm{N}$ concentrations were more than four times higher in the $\mathrm{F}$ treatment, while the $\mathrm{NO}_{3}{ }^{-} \mathrm{N}$ concentrations were five times higher in both $\mathrm{F}$ and IF treatments compared with the $\mathrm{C}$ treatment. As for total carbon and total nitrogen, their contents marginally differed across different treatments, with slightly lower values recorded in the control (C) treatment. Seasonal variations in basic soil characteristics were not observed in this study, and a good reproducibility was observed between two sampling seasons for nearly all the treatments (Fig. 1).

\section{Differentiations in potential nitrification rates (PNR) and abundances of $A O A$ and $A O B$}

PNR, serving as a maximal estimate of ammonia oxidation activity, were substantially altered after 6 years of 


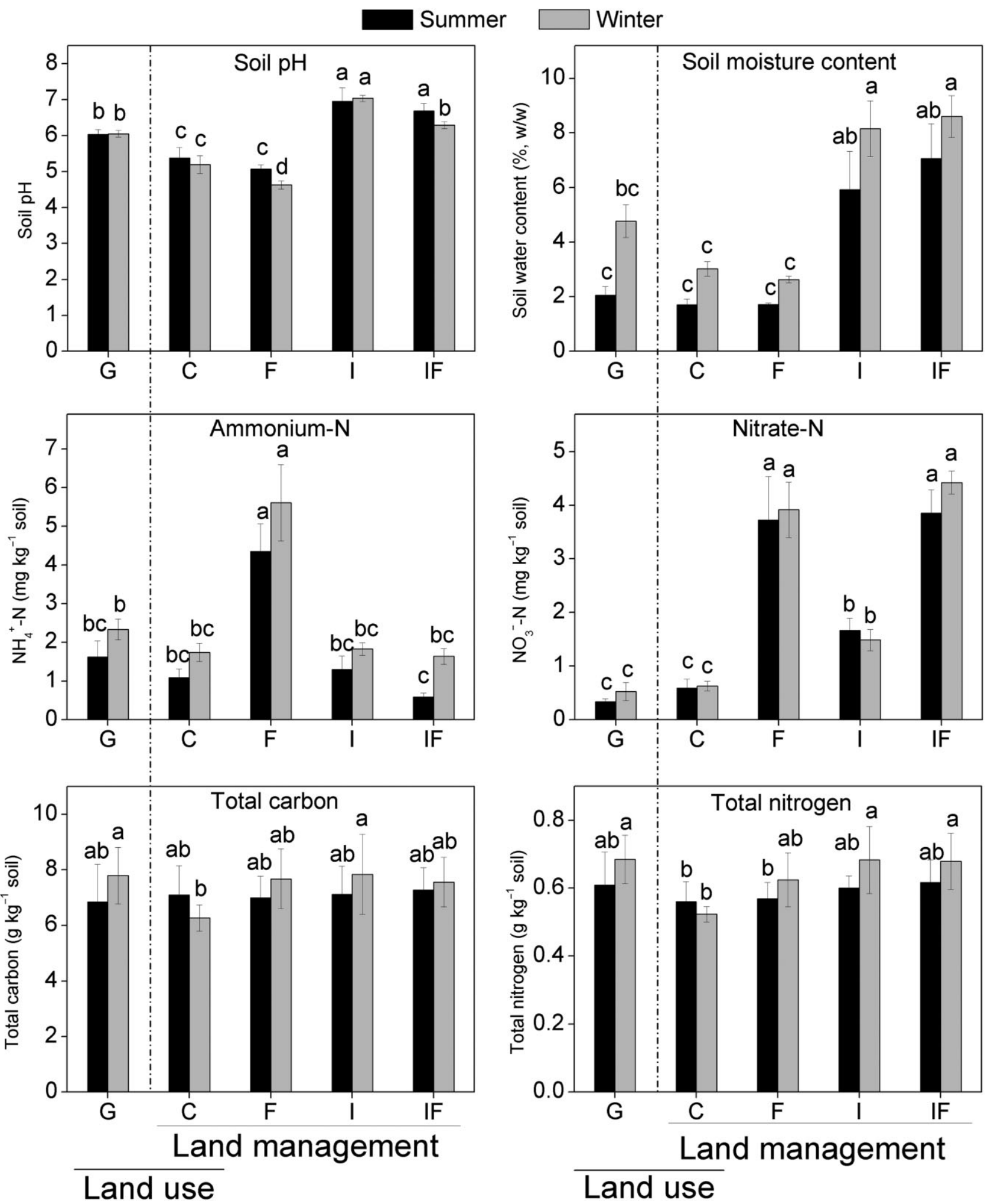

Fig. 1. Soil pH, soil moisture content, ammonium concentrations, nitrate concentrations, total carbon and total nitrogen across different land-management and land-use treatments (G, grassland; C, control; F, fertilization; I, irrigation; IF, irrigation + fertilization) at two sampling seasons. The 'land use' refers to the changes from grassland to forest (denoted as the 'control' treatment), and the 'land management' refers to the factorial combinations of irrigation and fertilization in only forests. Error bars represent standard errors $(n=4)$. Different letters above the bars indicate a significant difference $(P<0.05)$. 


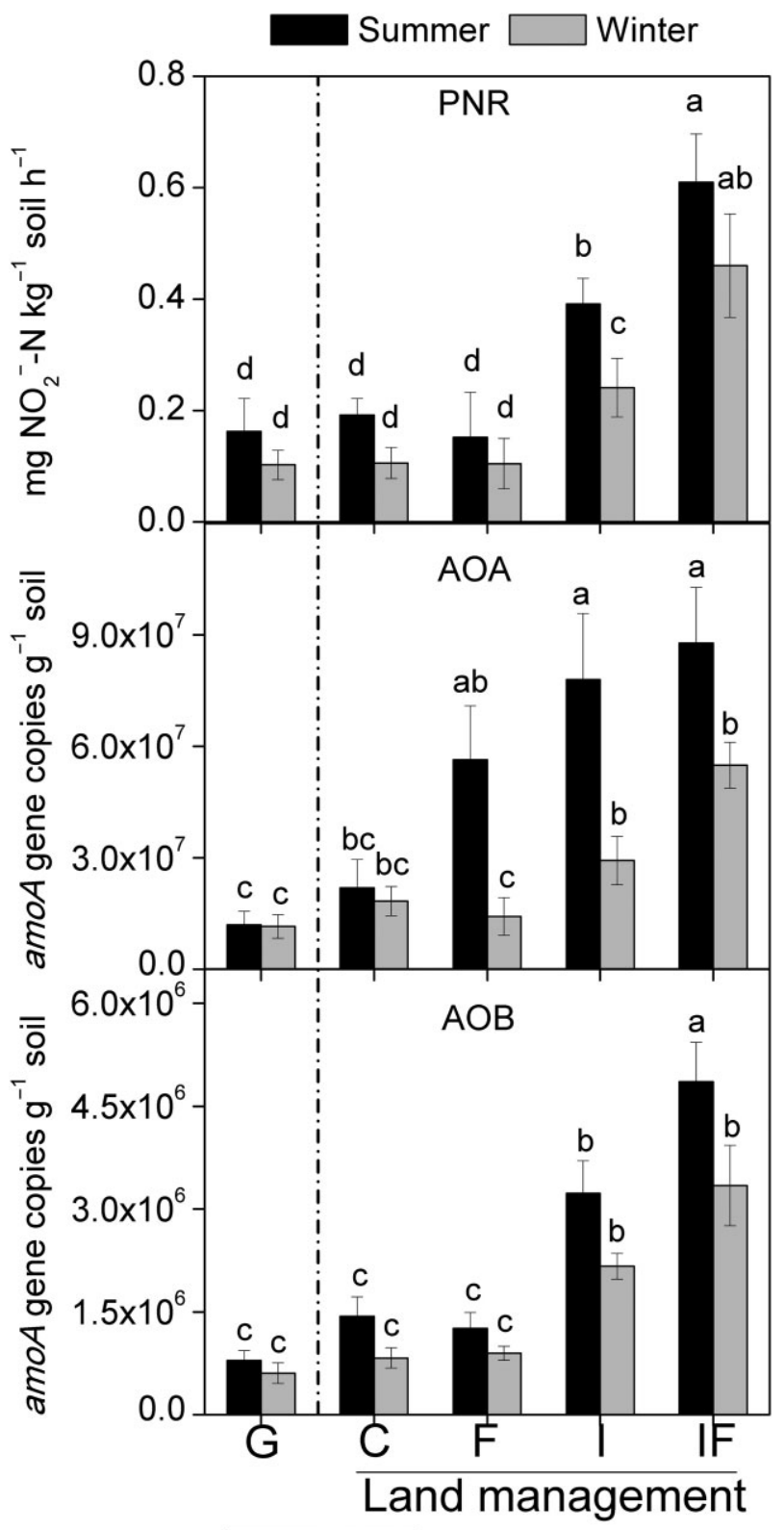

Land use

Fig. 2. $P N R$, abundance of $A O A$ and $A O B$ amo $A$ genes across different land-management and land-use treatments $(G$, grassland; $\mathrm{C}$, control; F, fertilization; I, irrigation; IF, irrigation + fertilization) at two sampling seasons. The 'land use' refers to the changes from grassland to forest (denoted as the 'control' treatment), and the 'land management' refers to the factorial combinations of irrigation and fertilization in only forests. Error bars represent standard errors $(n=4)$. Different letters above the bars indicate a significant difference $(P<0.05)$.

land-management practices, with $>100 \%$ higher rates found in the I and IF treatments, relative to the $\mathrm{C}$ treatment (Fig. 2). The copy numbers of AOA amo $A$ gene in all the treatments, varying from $1.15 \times 10^{7}$ to $8.78 \times 10^{7}$ copies $\mathrm{g}^{-1}$ soil, were more than 10 times higher than those of $\mathrm{AOB}$ amo $A$ gene, which ranged between
$6.06 \times 10^{5}$ and $4.86 \times 10^{6}$ copies g $^{-1}$ soil (Fig. 2). Consistent with the patterns of PNR, AOA and AOB abundances were greatly enhanced by I and IF. Identical patterns in the winter and summer samples across different treatments were observed for PNR, AOA and AOB abundances, but some seasonal effects were obvious in the I and IF treatments (Fig. 2). Both AOA and AOB abundances significantly correlated with PNR $(r=0.57$, $P<0.001 ; r=0.75, P<0.001$ respectively) when tested by Spearman's rank analysis.

\section{Community profiles of ammonia oxidizers by terminal-restriction length polymorphism (T-RFLP), cloning and sequencing}

The T-RFLP analysis of AOA amoA gene by the Rsal enzyme yielded 12 distinct terminal restriction fragments (TRFs) across all the treatments, of which TRF-196 and TRF-291 were the two most dominant genotypes (Fig. 3A). AOA community structures at two seasons were quite similar to each other, indicating that land-perturbation effects were constant at different sampling points. The relative abundance of TRF-196 and TRF-291 was significantly changed by the land-management practices, with TRF-196 significantly decreased and TRF-291 increased in the I and IF treatments. Cloning and sequencing analysis could assign phylogenetic affiliation to 11 TRFs (Supporting Information Fig. S1). Notably, TRF-196 and TRF-291 were placed within the Nitrososphaera and Nitrosotalea clusters, respectively, whereas TRF-614 and TRF-386, which tended to increase in the I and IF treatments (Fig. 3A), belonged to the Nitrosopumilus cluster. AOA community structure as revealed by the Bray-Curtis dissimilarity matrices clearly showed that the I and IF treatments harboured microbial assemblages distinct from other treatments (Fig. 3B). Permutational multivariate analysis of variance (PerMANOVA) analysis confirmed the significant dissimilarity in AOA community between treatments with or without irrigation $(P<0.05)$.

We further complimented the T-RFLP results of Rsal by using the HpyCH4V enzyme, which produced eight distinct TRFs (Supporting Information Fig. S2A). The digestion patterns of HpyCH4V were similar to those of Rsal, and we found that TRF-74 and TRF-160 significantly decreased and increased, respectively, in the I and IF treatments. Interestingly, sequencing analysis assigned TRF-74 and TRF-160 to Nitrososphaera and Nitrosotalea respectively (Supporting Information Fig. S1), which was consistent with the results of TRF-196 and TRF-291 digested by Rsal (Fig. 3A). Land management had a significant impact on AOA community structures, with the I and IF treatments harbouring $A O A$ communities distinct from the others regardless of the sampling time (PerMANOVA, $P<0.05$ ) (Supporting Information Fig. S2B). 
(A)

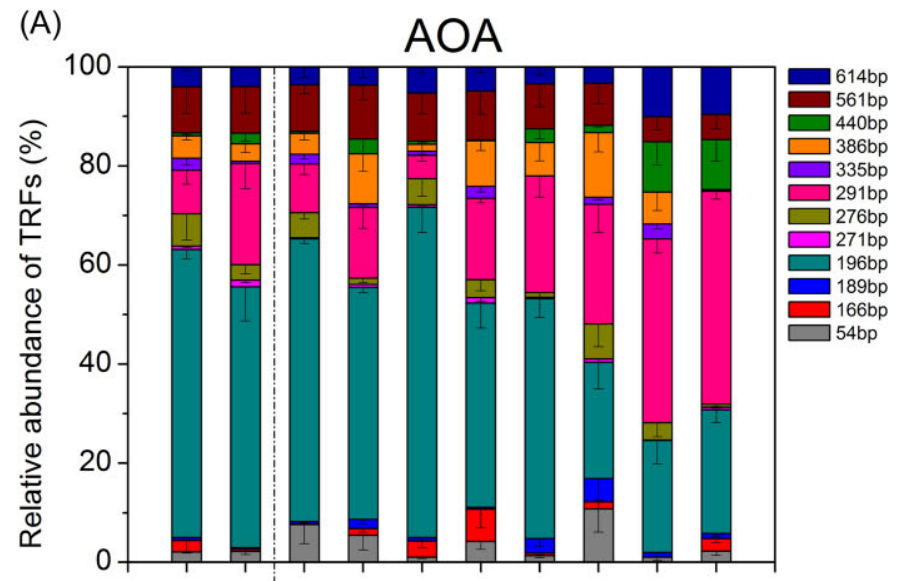

(C)
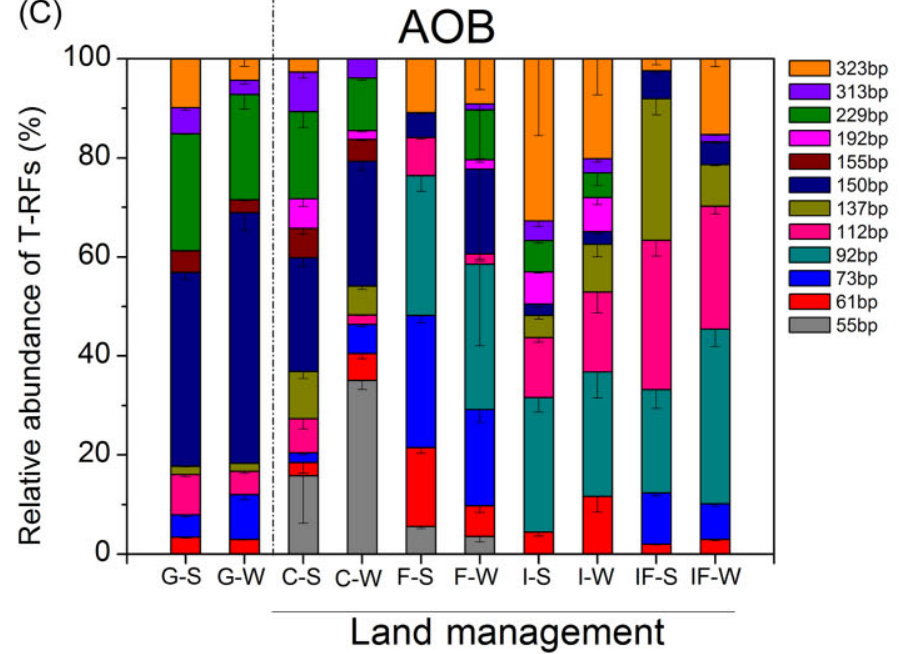

(B)

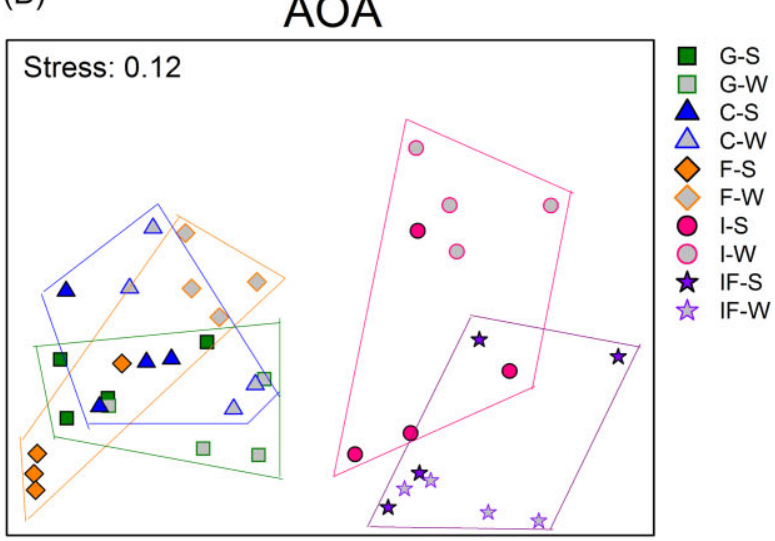

(D)
AOB

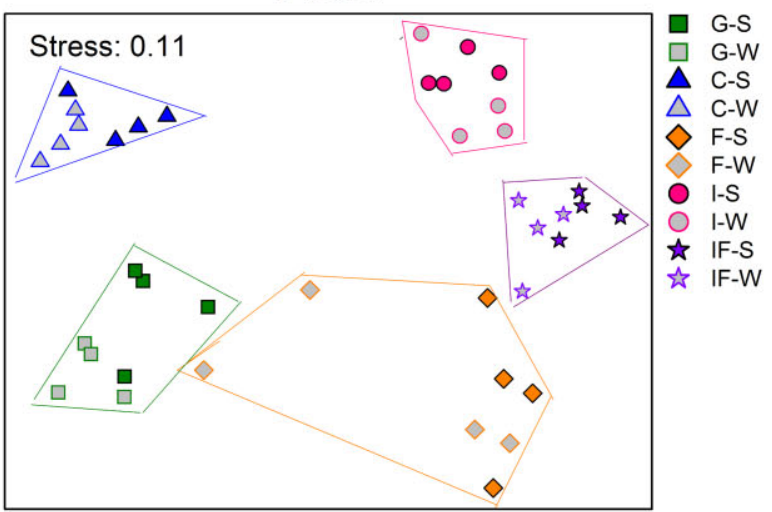

Land use

Fig. 3. Terminal restriction fragment length polymorphism fingerprints of the (A) AOA (digested using the Rsal enzyme) and (C) AOB (digested using the Mspl enzyme) amoA gene fragments across different treatments (G, grassland; C, control; F, fertilization; I, irrigation; IF, irrigation + fertilization; and $S$ and $W$ denote samples collected form spring and winter respectively). The 'land use' refers to the changes from grassland to forest (denoted as the 'control' treatment), and the 'land management' refers to the factorial combinations of irrigation and fertilization in only forests. Error bars represent standard errors $(n=4)$. NMDS ordinations derived from the Bray-Curtis dissimilarity matrices are based on the relative abundance of $(B) A O A$ and $(D)$ AOB terminal restriction fragments. The stress values for both NMDS plots were lower than 0.12 indicating that these data were well-represented by the two-dimensional ordinations.

Twelve distinct TRFs were obtained for $A O B$ amoA gene, of which TRF-92, TRF-112, TRF-150 and TRF-323 were the most dominant genotypes (Fig. 3C). AOB community structures seemed to be more similar in the same treatment at two seasons than those in different treatments. Differential adaptations of AOB TRFs to land perturbations were observed, for instance, TRF-92, TRF-112 and TRF-323 tended to be increased by I and IF, whereas TRF-150 and TRF-229 had higher frequency in the $G$ and $C$ treatments. Cloning and sequencing could assign phylogenetic affiliation to six AOB TRFs (TRF-61, 92, 150, 155, 192 and 229), and all of which were associated with the Nitrosospira cluster (Supporting Information Fig. S3). Non-metric multidimensional scaling (NMDS) based on the Bray-Curtis dissimilarity matrices revealed a clear divergence of $\mathrm{AOB}$ assemblages between different treatments (Fig. 3D), which was further corroborated by PerMANOVA analysis $(P<0.05)$.

\section{Community profiles of ammonia oxidizers by microarray}

The community compositions and phylogenetic distribution of $A O A$ and $A O B$ were further determined by highthroughput and high-resolution amoA-based microarray analysis (Abell et al., 2012). AOA microarray demonstrated positive signals for probes corresponding to a wide variety of phylotypes, which were highly divergent across different treatments (Fig. 4A). Intriguingly, higher hybridization signal intensity was observed for probes AmoA-175, AmoA-176, AmoA-177, AmoA-134, AmoA-135 and 
(A)

AOA

Hybridization intensity

$\begin{array}{llllll}0.0 & 0.2 & 0.4 & 0.6 & 0.8 & 1.0\end{array}$

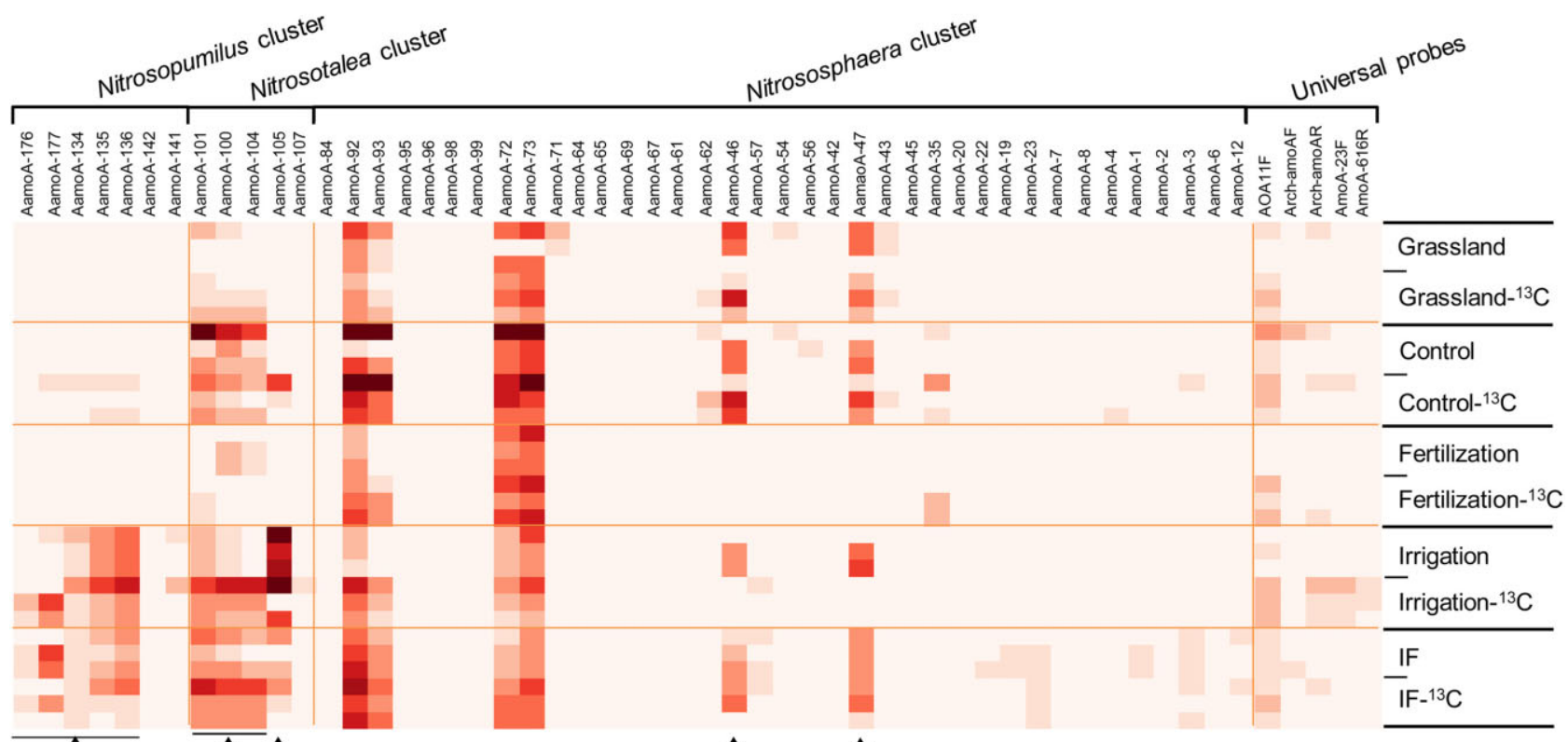

(B)

$\mathrm{AOB}$

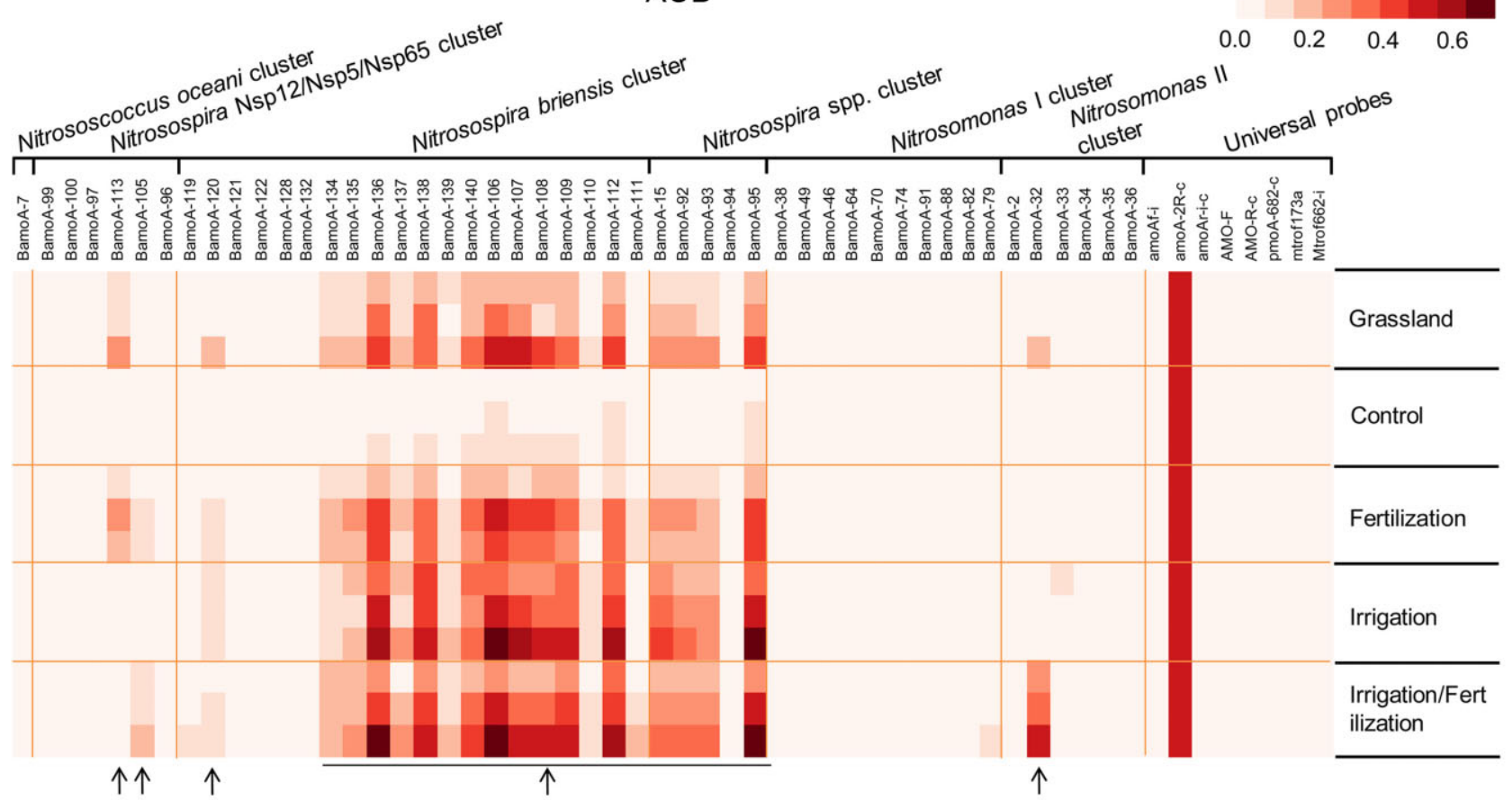

Fig. 4. Heat maps showing the amoA-based microarray results of $(A) A O A$ from total genomic DNA and ${ }^{13} C$-labelled DNA in the heavy SIP fractions and (B) AOB from total genomic DNA (B) across different treatments. Results of microarray were first normalized to the positive control probes, and then to the reference values determined individually for each probe. The probes with normalized signal intensity higher than 0.02 in at least one of the samples were displayed. The different colours as shown on the colour bar indicate the proportion of hybridization signals. Black arrows below the heat maps indicate the probes that are of particular interest in this study. 


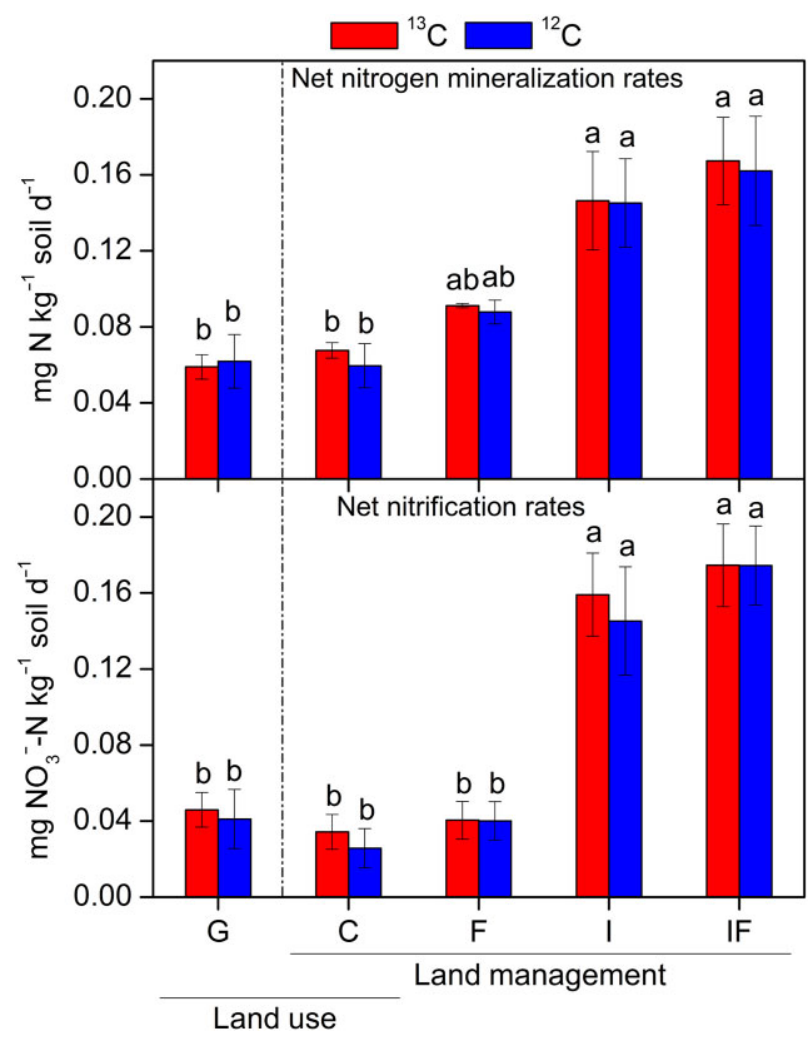

Fig. 5. Changes in net nitrogen mineralization rates and net nitrification rates across different treatments (G, grassland; C, control; F, fertilization; I, irrigation; IF, irrigation + fertilization) in the DNA-SIP microcosms after 30 days' incubation. The 'land use' refers to the changes from grassland to forest (denoted as the 'control' treatment), and the 'land management' refers to the factorial combinations of irrigation and fertilization in only forests. Error bars represent standard errors $(n=3)$. Different letters above the bars indicate a significant difference (analysis of variance, $P<0.05)$.

AmoA-136 targeting Nitrosopumilus in the I and IF treatments. Moreover, probes AmoA-101, AmoA-100, AmoA104 and in particular AmoA-105 targeting Nitrosotalea were highly positive in the $\mathrm{C}, \mathrm{I}$ and IF treatments, but very weak or absent in the $\mathrm{G}$ and $\mathrm{F}$ plots. The sequences related to Nitrososphaera were found to be present for 37 probes, of which AmoA-92, AmoA-93, AmoA-72 and AmoA-73 were strongly positive in all treatments, whereas AmoA-46 and AmoA-47 showed weak signals in the $F$ treatment. Striking differences in AOA community compositions were further corroborated by redundancy analysis, which showed the dominant roles of moisture and $\mathrm{pH}$ contributing to separation of I and IF plots from other treatments (Supporting Information Fig. S4).

Microarray analysis of $A O B$ demonstrated presence of sequences related to diverse clusters (Fig. 4B). Probes targeting the Nitrosospira briensis and Nitrosospira spp. clusters were strongly positive in all treatments with the exception of the $\mathrm{C}$ treatment. Some other interesting findings showing $\mathrm{AOB}$ community adaptation to different treatments included: strongly positive signals for probe BamoA-32 targeting the Nitrosomonas II cluster in the IF treatment; positive signals for probe BamoA-113 targeting the Nitrosospira Nsp12/Nsp5/Nsp65 cluster in the G and $F$ treatments; and positive signals for probe BamoA-105 in the $\mathrm{F}$ and IF treatments. We explored further the influences of environmental variables on distribution patterns of $\mathrm{AOB}$, and found soil $\mathrm{pH}$, nitrate and moisture as strong predictors (Supporting Information Fig. S5).

\section{Net nitrogen mineralization and net nitrification rates during the DNA-stable isotope probing (SIP) incubation}

Net nitrogen mineralization rates were calculated as the change in ammonium plus nitrate concentrations during the DNA-SIP incubation while net nitrification rates as the change in nitrate concentrations due to nitrate producing and consuming processes (Gleeson et al., 2010). Active mineralization and nitrification activity was observed in soil microcosms, and no significant differences were found between the ${ }^{13} \mathrm{CO}_{2}$ and ${ }^{12} \mathrm{CO}_{2}$ microcosms (Fig. 5), indicating that ${ }^{13} \mathrm{CO}_{2}$ did not result in apparent bias within nitrogen-cycling communities. Net nitrogen mineralization rates ranged from 0.059 to $0.167 \mathrm{mg} \mathrm{N} \mathrm{kg}^{-1}$ soil per day, and remarkably higher rates were recorded in the I and IF treatments. The $\mathrm{F}$ treatment tended to have a slightly higher mineralization rate than the $\mathrm{G}$ and $\mathrm{C}$ plots, but no significant differences were observed among them. The patterns of mineralization were highly similar to those of the net nitrification rates (Fig. 5), which were highly variable (0.026-0.175 $\mathrm{mg} \mathrm{NO}_{3}{ }^{-}-\mathrm{N} \mathrm{kg}^{-1}$ soil per day), with significantly higher nitrification rates found in the I and IF treatments. There was a strongly positive correlation between the rates of mineralization and nitrification $(r=0.79$, $P<0.001$ ), suggesting an important role of mineralized nitrogen substrate for the subsequent nitrification process.

\section{${ }^{13} \mathrm{C}$-labelled metabolically active ammonia oxidizers}

To provide more direct evidence for the active groups, soil samples collected from the field were immediately used in a month-long DNA-SIP microcosm incubation. Isopycnic gradient centrifugation was performed with genomic DNA isolated in triplicate from each treatment to separate the ${ }^{12} \mathrm{C}$-DNA from ${ }^{13} \mathrm{C}$-enriched-DNA for autotrophic ammonia oxidizers. The AOA abundance in ${ }^{12} \mathrm{CO}_{2}$ microcosms reached the maximal proportion in the light fractions around a buoyant density of $1.69 \mathrm{~g} \mathrm{ml}^{-1}$ (Fig. 6). After 30 days' incubation with ${ }^{13} \mathrm{CO}_{2}$, clear shifts to heavy fractions (1.71-1.73 $\left.\mathrm{g} \mathrm{ml}^{-1}\right)$, albeit to different extents across different treatments, were observed in AOA communities, implying incorporation of ${ }^{13} \mathrm{CO}_{2}$ into the genomic DNA of AOA during active nitrification. In the $\mathrm{G}, \mathrm{C}$ and $\mathrm{F}$ treatments, only a minor fraction of AOA was found in the 


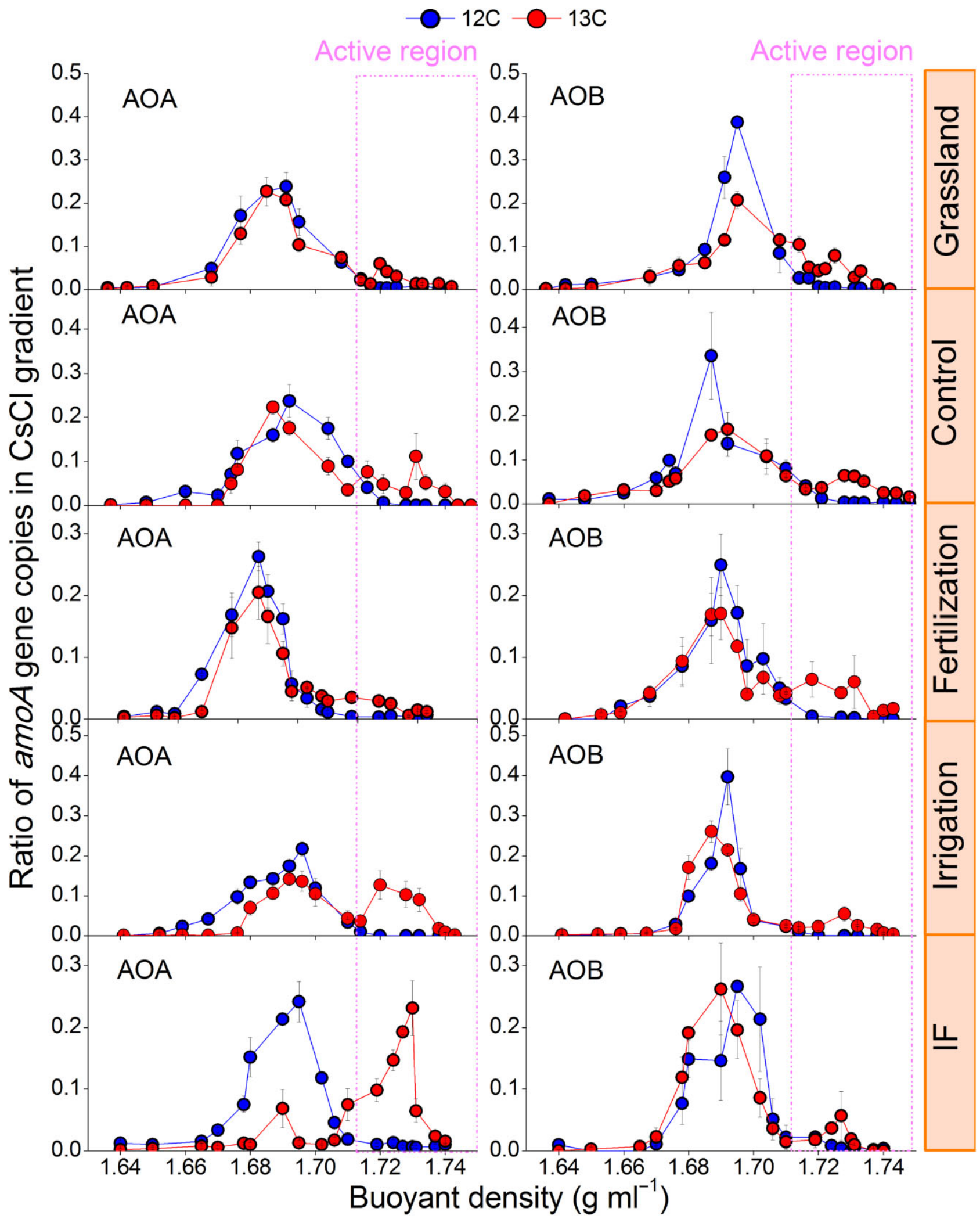

Fig. 6. Quantitative distributions of the relative abundance of $A O A$ and $A O B$ amoA genes retrieved from $\mathrm{CsCl}$ gradients for the ${ }^{13} \mathrm{C}-\mathrm{CO}_{2}$ and ${ }^{12} \mathrm{C}_{-} \mathrm{CO}_{2}$ treatments during DNA-SIP microcosms after 30 days' incubation. Eighteen fractions of genomic DNA extracted from each $1.8 \mathrm{ml}$ centrifuge tube covered a buoyant density gradient from 1.64 to $1.75 \mathrm{~g} \mathrm{ml}^{-1}$. The plotted values are the proportion of AOA or AOB amoA gene copy numbers in each fraction to the total abundance across the entire gradient. Error bars represent standard errors $(n=3)$. 


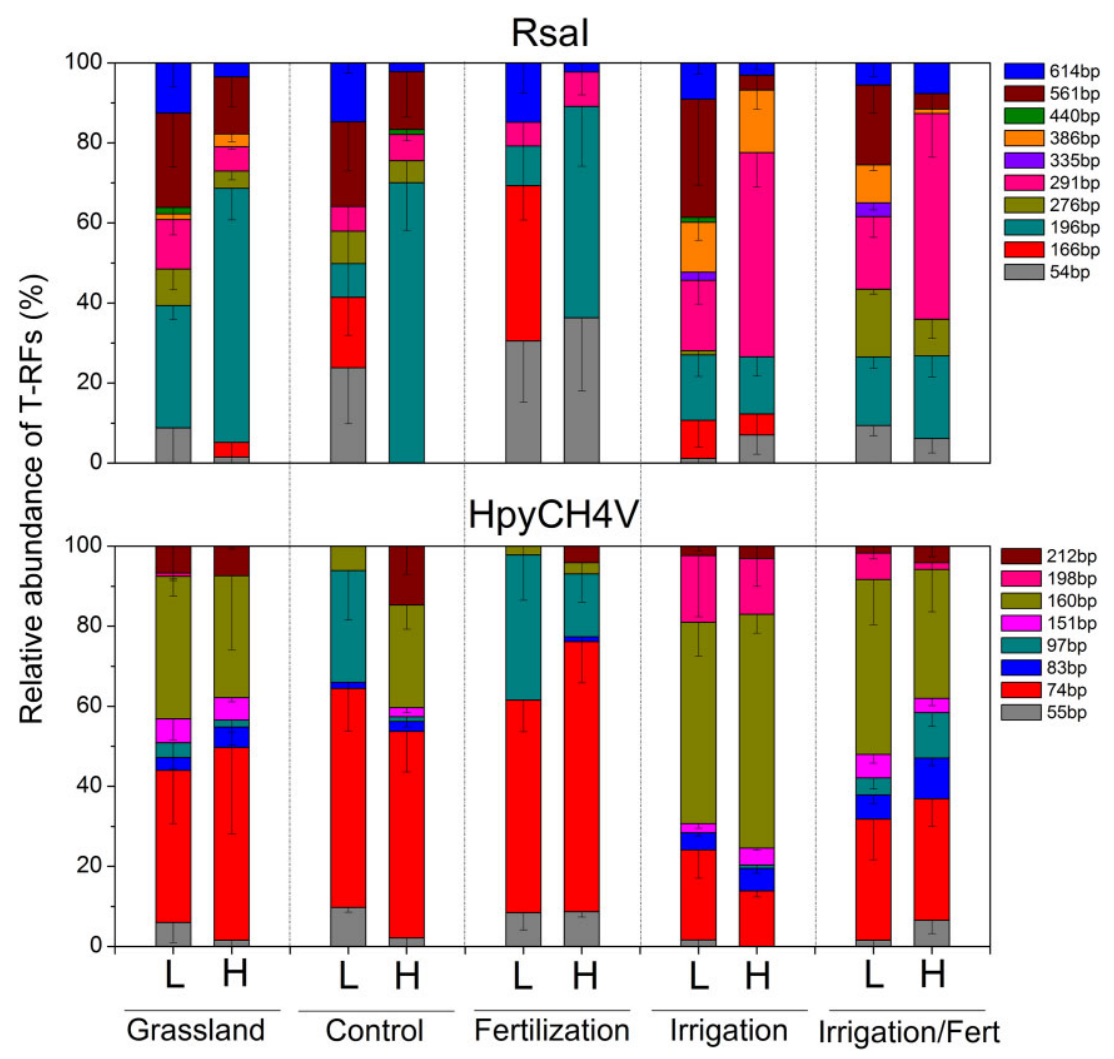

Fig. 7. Comparisons of T-RFLP fingerprinting of the AOA amoA gene TRFs (digested using the Rsal or HpyCH4V enzyme) from both light $(L)$ and heavy $(H)$ SIP fractions across different treatments. Error bars represent standard errors $(n=3)$.

'active region' (Fig. 6), and a major fraction of AOA was metabolically inactive and stayed in the light SIP regions. Increasing ${ }^{13} \mathrm{C}$-labelling of AOA, however, was detected with approximate $50 \%$ of them in the active region for the I treatment and with more than $90 \%$ in the active region for the IF treatment. By contrast, the AOB abundance in both ${ }^{12} \mathrm{CO}_{2}$ and ${ }^{13} \mathrm{CO}_{2}$ microcosms peaked only in the light fractions around a buoyant density of $1.695 \mathrm{~g} \mathrm{ml}^{-1}$ (Fig. 6), suggesting that a major fraction of AOB stayed inactive during the DNA-SIP incubation. The active populations constituted a remarkably low percentage of the total AOB community and decreased to a lesser extent in the I and IF treatments.

AOA amoA gene polymerase chain reaction (PCR) products retrieved from both light and heavy SIP fractions were subjected to T-RFLP analysis, which produced contrasting fingerprinting patterns between the 'inactive' and 'active' groups for nearly all the treatments (Fig. 7). As for the dataset digested by Rsal, TRF-291 (belonging to Nitrosotalea) was observed to constitute a large proportion of AOA community in the heavy SIP fractions of the I and IF treatments, whereas TRF-54 and TRF-196 (belonging to Nitrososphaera) was found to be more actively assimilating ${ }^{13} \mathrm{CO}_{2}$ in other three treatments. These findings were further confirmed by the dataset of $\mathrm{HpyCH} 4 \mathrm{~V}$, which found similar influences of land perturbations on the ${ }^{13} \mathrm{C}$-labelling of TRF-160 (belonging to Nitrosotalea) and TRF-74 (belonging to Nitrososphaera).
High-throughput microarray was also performed to elucidate the metabolically active AOA members retrieved from the heavy SIP fractions, which suggested that the majority of $\mathrm{AOA}$ are capable of synthesizing ${ }^{13} \mathrm{C}$-DNA under microcosm conditions (Fig. 4A). Generally, the hybridization patterns of the active AOA community either resembled those of the total AOA community or represented a subset of them. Diverse probes targeting Nitrosopumilus, Nitrosotalea and Nitrososphaera were found to be highly positive in the I and IF treatments, indicating the favourable effects of water addition on metabolic activity of AOA. Similar to redundancy analysis of the total AOA community, we found that the active AOA community was separated between the treatments with or without irrigation, which was also dominantly regulated by soil moisture contents and $\mathrm{pH}$ (data not shown). Unfortunately, we failed to obtain sufficient PCR amplicons for $A O B$ microarray analysis in the heavy SIP regions because of the considerably low $\mathrm{AOB}$ abundance in these fractions (Fig. 6).

\section{Discussion}

Irrigation has more important roles than fertilization in impacting ammonia oxidation within dryland forest soils

Recent studies have shown contrasting effects of nitrogen fertilization on $\mathrm{AOA}$ and $\mathrm{AOB}$ in agricultural and grassland soils (He et al., 2007; Di et al., 2009); for instance, in 
upland red soils, AOA community composition responded dramatically to different long-term field fertilization regimes (He et al., 2007), whereas in alkaline sandy loam, changes of $\mathrm{AOB}$ abundance and community composition were found to be more obvious (Shen et al., 2008). The differential responses of ammonia oxidation to fertilization regimes were generally attributed to the divergent affinity and sensitivity of $A O A$ and $A O B$ to ammonia substrate, and ammonia availability in soils was recognized as a direct factor contributing to metabolic divergence of ammonia oxidizers (Verhamme et al., 2011; He et al., 2012; Hu et al., 2014). In the fertilization plots of this study, the concentrations of ammonium and nitrate were significantly enhanced after 6 years' treatment. Surprisingly, this did not result in any significant changes in potential/net nitrification rates, or abundance and metabolic activity of AOA and AOB. By comparison, the field plots receiving only water addition exhibited higher potential/net nitrification rates and $\mathrm{AOB}$ and $\mathrm{AOA}$ abundances, and metabolic activity of the latter was stimulated to a greater extent in the plots receiving both water and fertilizer addition (Fig. 6). Therefore, the effects of fertilizers on ammonia oxidation are not obvious unless concomitantly amended with water, which highlights the significance of water in ammonia oxidation of the examined dryland forest soils.

There has been evidence suggesting the impacts of availability of water on soil biogeochemical processes across various biomes and climatic conditions (Manzoni et al., 2012), and the microbial and functioning responses to availability of water are remarkably more apparent and positive in arid and semi-arid soils. It was found that soil nitrogen transformation rates were relatively higher after rainfalls than during dry periods (Austin et al., 2004), and abundance and community structure of ammonia oxidizers were highly responsive to water-filled pore space in a grassland soil (Gleeson et al., 2010). Likewise, in laboratory microcosms incubated with dry grassland soils, ammonia oxidizers exhibited rapid responses to water addition with an increase in $a m o A$ gene transcripts within $1 \mathrm{~h}$ of wet-up (Placella and Firestone, 2013), and nitrification potential and nitrate concentrations responded positively to increasing soil moisture contents and fertilizers (Avrahami and Bohannan, 2007). In this study, using a combined approach to process nitrogen transformation rates, microbial communities and active groups, we provide novel evidence that in dryland forests, availability of water play a regulatory role in nitrification rates irrespective of substrate supply.

The water contents in the control and fertilization treatments at the time of sampling were around $2 \%$; thus, soil samples before irrigation could be considered as a waterlimited dry environment. Although higher ammonium concentrations were found in the fertilization treatment, dry conditions in these plots likely reduced substrate and enzyme mobility (Stark and Firestone, 1995), and decreased the substrate supply to ammonia oxidizers. These negative effects of water deficiency on ammonia availability can be explained by three possible mechanisms. Firstly, in dry soils, water-filled soil capillaries become disconnected (Manzoni et al., 2012), and water films coating surfaces become thinner; thus, diffusion path lengths for substrate will become more tortuous, which could decline the rates of substrate diffusion to ammonia oxidizers. Therefore, ammonia oxidizers have difficulties to access the already-present ammonium substrate (e.g. in the control treatment) or added ammonium (e.g. in the fertilization treatment) because of the diffusional limitation of substrates under dry conditions. Secondly, microbial activity could be declined or inhibited by low availability of water via lowering intracellular water potential, reducing hydration and activity of enzymes, and causing negative physiologic effects associated with cell dehydration (Stark and Firestone, 1995). This mechanism could be able to explain why the majority of $A O A$ and $A O B$ community remained inactive or dormant in the control and fertilization treatments (Fig. 6). Thirdly, low water contents would increase the concentrations of sulfate and phosphate solutes, which have been demonstrated to strongly rigidify cell membranes and other cellular macromolecules (Cray et al., 2013b). Numerous studies have shown that chao-/kosmotropicity of solutes could impact the windows for microbial metabolism and growth, which in turn might lead to the low nitrification activity of ammonia oxidizers (Hallsworth et al., 2007; Williams and Hallsworth, 2009; Cray et al., 2013a). These negative effects on ammonia oxidizers will collectively impair their capacity and rates to oxidize ammonia, so we found lowlevel potential and net nitrification rates in the control and fertilization treatments.

However, access to ammonia substrate in dry soils cannot be overcome by physiological adaptation of ammonia oxidizers or addition of fertilizers, but the stress could be relieved by water addition. Previous studies have found that increased soil moisture could accelerate nitrogen mineralization rates, thereby supporting higher rates of nitrification (Stark and Firestone, 1995). The rewetting of dry soils was reported to cause an abrupt flush of nutrients from the mineralization burst upon wet-up events (Borken and Matzner, 2009). As evidenced in this study, when water contents were elevated to be higher than $6 \%$ by irrigation, net nitrogen mineralization rates were significantly stimulated, which subsequently led to increased net nitrification rates (Fig. 5). One mechanism postulated that water addition could improve soil hydraulic conditions by connecting microbes with substrates (Schaeffer et al., 2013), and increase the microbial activity of mineralizers and nitrifiers by removing water stress. 
Another possible mechanism is that, under dry conditions, soil solution becomes more concentrated, microbial cells must accumulate intracellular solutes (e.g. amino compounds or polyols) to reduce their internal water potential, by which to avoid dehydrating and dying (Schimel et al., 2007). However, when dry soils become wetted, microorganisms have to dispose of intracellular solutes again to equilibrate cellular water potentials with surrounding water, which might release a high flux of nutrients into soils (Schimel et al., 2007); these biologically liable materials could be subsequently used by a wide variety of mineralizers to produce ammonia resources for ammonia oxidation. Furthermore, recent studies provided strong evidence that water addition could cause hypo-osmotic or dilution stress in soil environments, and the inhabitant microbes would have a high rate of metabolism and growth when solutes are present concurrently (Williams and Hallsworth, 2009). This phenomenon held true in this study by observing a higher nitrification rates in the irrigation + fertilization treatment (receiving more solutes) than that in the irrigation treatment.

Aside from the direct effects of elevated availability of water induced by irrigation, we should also note that irrigation caused an obvious elevation in soil pH (Fig. 1), the importance of which in impacting ammonia oxidation has been greatly recognized in previous studies (Zhang et al., 2012; Hu et al., 2013; Yao et al., 2013) and also confirmed by redundancy analysis in the present study (Supporting Information Figs S4 and S5). Soil pH was significantly increased to be near neutral by the irrigation and irrigation + fertilization treatments, which could elevate the amount of $\mathrm{NH}_{3}$ relative to $\mathrm{NH}_{4}{ }^{+}$in soil solution (He et al., 2012; Hu et al., 2014); therefore. a high ammonia availability could also be expected. However, the multiple regression analysis found that the land-management treatment effects $(P<0.001)$, rather than soil $\mathrm{pH}$ $(P=0.725)$, are explanatory variables that could significantly predict PNR. These results indicate that the irrigation treatment has a dominant effect on nitrification activity independent of the other soil variables.

\section{Subtle effects of land-use changes on ammonia oxidation is attributed to low availability of water}

The balance of nitrogen cycle is often disturbed by conversion of ecosystems, for instance, from grassland to forest and vice versa, which is a widespread occurrence affecting terrestrial ecosystem functioning and biodiversity (Lauber et al., 2008). The significant importance of land-use types in shaping the abundance and community compositions of ammonia oxidizers has been established in a large-scale molecular investigation (Yao et al., 2013) and in several local-scale surveys (Ying et al., 2010; Shen et al., 2013). Grassland and forest ecosystems might differ in the rates they allocate photosyntheric carbon sources belowground, which would affect the quantity and quality of root exudates and nutrients, and ultimately affecting the mineralized ammonia available for ammonia oxidizers. In this study, however, no significant differences in ammonium concentrations and net nitrogen mineralization rates between grassland and forest soils could be observed, indicating that energy flux for ammonia oxidation was not significantly altered by landuse changes. Although the community structures of ammonia oxidizers determined by microarray were highly divergent between grassland and forest (control) soils, we did not find significant differences in potential/net nitrification rates or metabolic activity of $\mathrm{AOA}$ and $\mathrm{AOB}$.

Apart from the plant-associated substrates, adaption of ammonia oxidizers to land-use changes might also be influenced by multiple abiotic factors. Afforestation of grassland with forests significantly decreased soil $\mathrm{pH}$, total carbon and nitrogen (Fig. 1), which were recognized as fundamental factors driving the biogeographic patterns of ammonia oxidizers ( $\mathrm{Hu}$ et al., 2013), and also represented the critical indicators for energy status and basal metabolisms in soils. Previous investigations across a wide range of land-use types have also shown that edaphic properties had an important role in shaping microbial community compositions and activity (Lauber et al., 2008). However, these significant differences in $\mathrm{pH}$ and total nitrogen between the grassland and control plots did not result in obvious changes in nitrification activity or functioning of ammonia oxidizers. This is because that these Eucalyptus forests are very young, and a previous study (Nazaries et al., 2011) suggested that change in functional microbial (methane oxidizing) community takes place first and change in activity rates follows at a later stage. Therefore, it is possible that change in nitrification rates due to land-use changes may appear in next few years. As discussed above for subtle effects of fertilization, the lack of land-use effects might be also explained by the lower availability of water in the examined soils. Although the quantity and quality of nutrients might differ between grassland and forest soils, the nutrients diffusion to ammonia oxidizers could be seriously impaired by water starvation; therefore, the substrates actually available for ammonia oxidation might be very limited, which was difficult to induce any metabolic differences between $\mathrm{AOA}$ and $\mathrm{AOB}$. Other studies also demonstrated that harsh environments could highly reduce the variation of microbial community (Pointing et al., 2009). For instance, in energy-poor Antarctic soils, ammonia oxidizers did not show any feedback responses to environmental perturbations (Schafer et al., 2007); and in ammonia-poor acidic peat soils, AOA ammonia oxidation did not respond to fertilizer amendments (Stopnišek et al., 2010). 
Increasing involvement of AOA in nitrification when dry soils become wetted

Recent studies have suggested that changes in water availability could lead to niche separation of inhabitant microbes with different ability of stress tolerance and nutrient acquisition (Cray et al., 2013a). Ammonia oxidation is controlled by the metabolically active ammonia oxidizers. In this study, by employing ${ }^{13} \mathrm{CO}_{2}$-DNA-SIP microcosms, we provided strong evidence for differential impacts of land-perturbation practices on the metabolic activity of ammonia oxidizers, which are actively growing, reproducing and involved in the utilization of ${ }^{13} \mathrm{CO}_{2}$ substrates. In the grassland, control and fertilization treatments, only a minor fraction of $A O A$ and $A O B$ was labelled by ${ }^{13} \mathrm{CO}_{2}$, indicating that most of ammonia oxidizers in these plots stayed less active or dormant under dry conditions. Soil microorganisms might enter a reduced or dormant state in face of stressful conditions (Lennon and Jones, 2011); however, these species are capable of being resuscitated and contribute to function when favourable environmental conditions appear. Our findings supported this hypothesis by observing strikingly increased labelling of $A O A$, but not $A O B$, in the irrigation and irrigation + fertilization treatments, where advantageous conditions with sufficient water and ammonia resources might increase cell maintenance and survival of AOA and concomitantly increase their capacity of oxidizing ammonia.

The clear niche differentiation between AOA and AOB in the irrigation and irrigation + fertilization treatments could be attributed to AOA's preference and higher affinity for ammonia resources generated from high rates of nitrogen mineralization in these plots, which was supposed to support the active AOA nitrification in several ammonia-poor soils (Stopnišek et al., 2010; He et al., 2012; Zhang et al., 2012). A synthetic survey of nitrogen cycling rates in terrestrial ecosystems found that nitrification was largely dependent on nitrogen mineralization, indicating an important role of mineralized ammonia substrate for the subsequent nitrification transformations (Booth et al., 2005). In soil microcosm studies, AOA growth responded positively to liable organic materials from root exudation in paddy rhizosphere soil (Chen et al., 2008) and pronounced stimulation effects of pig manure amendment on AOA growth were demonstrated in a silt loam soil (Schauss et al., 2009). These studies clearly indicated that continuous flux of ammonia released from mineralization is the direct substrate fueling AOA ammonia oxidation in ammonia-poor soils. Considering the water-induced changes of energy flux in arid and semi-arid soils (Schimel et al., 2007), we propose that, in dryland ecosystems, water addition might selectively afford AOA greater ecological advan- tage for rapid growth on labile organic matters released into soil or on the ammonia substrate produced by increased mineralization.

Sequencing and microarray analyses of AOA retrieved from ${ }^{13} \mathrm{CO}_{2}$-labelled heavy SIP fractions revealed that the active AOA community responsible for ammonia oxidation was affiliated with Nitrosopumilus, Nitrosotalea and Nitrososphaera. Previous studies have directly linked Nitrososphaera with autotrophic nitrification in acidic (Zhang et al., 2012) and alkaline agricultural soils (Xia et al., 2011), and our findings further expanded their functional importance to the arid and semi-arid grass and forest lands. Large-scale pyrosequencing investigations also found that Nitrososphaera was the most abundant AOA cluster, prevailing in a wide variety of terrestrial ecosystems (Gubry-Rangin et al., 2011; Hu et al., 2013). Genomic annotations of the Nitrososphaera strains also provided insights into their genomic capacity of using various ammonia sources and flexible carbon metabolism, which facilitate their metabolic versatility and physiological adaptations under different environmental conditions (Spang et al., 2012). Therefore, we supposed that numerously abundant Nitrososphaera might be also functionally important in various soil environments. Moreover, Nitrosotalea was generally found to be functionally active in acidic soils (Zhang et al., 2012); however, our study provided new traits of Nitrosotalea that metabolic activity of this cluster was strongly inhibited by nitrogen fertilization, but exhibited positive responses to water amendment (even $\mathrm{pH}$ is around neutral in the irrigation and irrigation + fertilization treatments). In addition, Nitrosopumilus, originally obtained from marine environments, could be also actively assimilating ${ }^{13} \mathrm{CO}_{2}$ in the irrigated plots, implying a niche preference of this cluster to soils with favourable moisture contents, rather than water-limited conditions. Therefore, the ecological importance of Nitrosopumilus, albeit representing a minor group in soils (Hu et al., 2013), might be more significant in nitrification following rainfall or other wetting-up events like irrigation.

Although the ${ }^{13} \mathrm{CO}_{2}$ incorporation of $\mathrm{AOA}$ was well related to potential/net nitrification rates, we should keep cautious when interpreting these results. Very recently, the perception of autotrophic growth of AOA was challenged by the amoA-containing $\mathrm{AOA}$ affiliated with Nitrososphaera in a refinery nitrifying sludge lacking the capacity to incorporate $\mathrm{CO}_{2}$, pointing to a heterotrophic growth through biodegradation of organic matters (Mußmann et al., 2011). Hence, the possible activity of these AOA (or AOB possessing the similar characteristics) would be ignored in this DNA-SIP study. In addition, the labelling of active ammonia oxidizers to indicate the nitrification activity is based on the assumption that activity and growth are synonymous; however, not all 
metabolically active organisms are definitely growing and replicating (Pratscher et al., 2011). For instance, the nongrowing $A O B$ that cannot be detected by the DNA-SIP might also be involved in the nitrification processes. Considering the close correlation between the AOB abundance and PNR, and the significant influences of land-use and land-management practices on the AOB community structures, future studies should include more direct measurement of $\mathrm{AOB}$ amoA gene expression and the corresponding enzymatic activity in combination with SIP.

\section{Conclusions}

In conclusion, by employing a polyphasic approach combining molecular methods and stable isotope probing, we provided comprehensive evidence that effects of landmanagement and land-use practices on autotrophic ammonia oxidation in dry subhumid ecosystems are primarily regulated by availability of water. Our results suggested that in arid or semi-arid ecosystems, water addition had much more dominant impacts than fertilizer addition in affecting autotrophic nitrification and thereby plant nutrient availability. Metabolic activity of AOA and $A O B$ exhibited differential feedback responses to water addition, with $A O A$ increasingly involved in the enhanced nitrification activity in the irrigated plots. Our findings have direct implication for impacts of land-management practices on nitrification under future climatic conditions because of the predicted increase in desertification and frequent fluctuations in availability of water induced by altered precipitations and irrigation regimes.

\section{Experimental procedures}

\section{Field site description and soil sampling}

The experimental field is situated at the Hawkesbury Forest Experiment site $\left(33^{\circ} 36^{\prime} 40^{\prime \prime} \mathrm{S}, 150^{\circ} 44^{\prime} 26.5^{\prime \prime} \mathrm{E}\right)$, University of Western Sydney, Richmond, NSW, Australia. The soil in this site is an alluvial formation of sandy loam characterized by low organic matter content $(0.7 \%)$, low water contents $(<3 \%)$, and low fertility [N $\left(<1 \mathrm{mg} \mathrm{kg}^{-1}\right), \mathrm{P}\left(8 \mathrm{mg} \mathrm{kg}^{-1}\right), \mathrm{S}$ $\left(5 \mathrm{mg} \mathrm{kg}^{-1}\right), \quad$ B $\quad\left(0.2 \mathrm{mg} \mathrm{kg}^{-1}\right), \quad \mathrm{Zn} \quad\left(0.9 \mathrm{mg} \mathrm{kg}^{-1}\right), \quad \mathrm{Cu}$ $\left(0.2 \mathrm{mg} \mathrm{kg}^{-1}\right), \quad \mathrm{Fe} \quad\left(24 \mathrm{mg} \mathrm{kg}^{-1}\right), \quad \mathrm{Mn} \quad\left(9.1 \mathrm{mg} \mathrm{kg}^{-1}\right), \quad \mathrm{Cl}$ $\left(13 \mathrm{mg} \mathrm{kg}^{-1}\right)$ and exchangeable cations $\mathrm{Al}(0.14 \mathrm{meq}$ $\left.100 \mathrm{~g}^{-1}\right)$, K (0.23 meq $\left.100 \mathrm{~g}^{-1}\right)$, Ca (1.2 meq $\left.100 \mathrm{~g}^{-1}\right)$, Mg $\left(0.34\right.$ meq $\left.100 \mathrm{~g}^{-1}\right)$ and $\mathrm{Na}\left(0.1 \mathrm{meq} 100 \mathrm{~g}^{-1}\right)$ ] (Barton et al., 2010). The mean annual temperature at the site is $17^{\circ} \mathrm{C}$, and the average annual precipitation is $801 \mathrm{~mm}$, with a precipitation/evapotranspiration ratio of 0.6 , classifying it as a dry subhumid environment under UNEP classification (Millennium Ecosystem Assessment, 2005).

The irrigation plus fertilization field experiment was established in 2007 including four treatments: control (C), irrigation (I), fertilization (F) and irrigation + fertilization (IF). Each treatment has four replicate plots $(38.5 \times 41.6 \mathrm{~m})$ in a randomized block design. This site was planted with Eucalyptus saligna in
April 2007, and all trees were initially supplied with $50 \mathrm{~g}$ diammonium phosphate starter blend (N 15.3\%, P 8.0\%, K $16.0 \%, \mathrm{~S} 7.7 \%$ and $\mathrm{Ca} 0.3 \%$ ) per plant to promote establishment. The first fertilization in the $\mathrm{F}$ and IF treatments was undertaken in January 2008 as a solid $\mathrm{N}$ fertilizer (N 20.6\%, P 3.0\%, K 7.5\%, S 3.8\%, Ca 4.4\%) at a rate of $25 \mathrm{~kg} \mathrm{~N} \mathrm{ha}^{-1}$ year ${ }^{-1}$. In October 2008, solid N fertilizer (N 21.6\%, P 8.1\%, K $12.0 \%, \mathrm{~S} 0.6 \%$ ) at a rate of $150 \mathrm{~kg} \mathrm{~N} \mathrm{ha}^{-1}$ year $^{-1}$ was started to apply uniformly to the $\mathrm{F}$ treatment. In the I treatment, water was supplied at a rate of $15 \mathrm{~mm}$ every 4 days from September to April, and 7-10 mm every 4 days from April to September. Therefore, the irrigated plots received c. $1000 \mathrm{~mm}$ year $^{-1}$ plus the ambient rainfall. The IF treatment started in October 2008, with addition of a complete liquid fertilizer at a rate of $150 \mathrm{~kg} \mathrm{~N} \mathrm{ha}^{-1}$ year-1. The total amount of water added into the IF treatment was the same to the I treatment. More detailed information on treatments, plant and insect responses are included in Frew and colleagues (2013).

Soil samples were collected from the 24 plots in November 2012 (summer) and May 2013 (winter), including the adjacent grassland $(G)$ soils. No fertilization or irrigation has been recorded in these pasture grasslands. In each of the four replicate plots, five soil cores $(2.5 \mathrm{~cm}$ in diameter and $15 \mathrm{~cm}$ depth) were randomly taken. The subsamples were pooled and homogenized into a composite sample for each plot, sieved through a $2.0 \mathrm{~mm}$ mesh, and stored at $-80^{\circ} \mathrm{C}$ before DNA extraction and at $4^{\circ} \mathrm{C}$ before physicochemical analyses.

\section{DNA extraction and physicochemical analysis}

The total genomic DNA was isolated from $0.25 \mathrm{~g}$ of soil using the MoBio PowerSoil DNA Isolation Kit (MoBio Laboratories, Carlsbad, CA, USA) according to the manufacturer's instructions, with slight modifications that a FastPrep bead beating system (Bio-101, Vista, CA, USA) at a speed of $5.5 \mathrm{~m} \mathrm{~s}^{-1}$ for $30 \mathrm{~s}$ was used at the initial cell-lysis step. The quantity and quality of extracted DNA were checked photometrically using NanoDrop ${ }^{\circledR}$ ND-2000c UV-Vis spectrophotometer (NanoDrop Technologies, Wilmington, DE, USA). Soil ammonium and nitrate were extracted from fresh soils $(5 \mathrm{~g})$ with $25 \mathrm{ml}$ of $2 \mathrm{M}$ $\mathrm{KCl}$ by shaking at 170 r.p.m. for $60 \mathrm{~min}$, and the filtered solution was used to be determined by a SEAL AQ2 Analyzer (SEAL Analytical, Maquon, WI, USA). Soil pH was measured using a fresh soil to water ratio of 2.5 with a Delta $\mathrm{pH}-$ meter (Mettler-Toledo Instruments, Columbus, OH, USA). Soil moisture content was measured by oven-drying the samples at $105^{\circ} \mathrm{C}$ for $24 \mathrm{~h}$. Total carbon and total nitrogen were measured on a LECO macro-CN analyzer (LECO, St Joseph, MI, USA).

\section{PNR measurement}

PNR were assessed within 3 days after collecting samples from the field using the chlorate inhibition soil-slurry method as previously described (Kurola et al., 2005). It has been suggested that adjustment of soil slurry $\mathrm{pH}$ to 7.1 might limit growth of acidophilic strains (Prosser and Nicol, 2012); hence in this study, nitrification potential was measured at the natural soil $\mathrm{pH}$ without adjustment of slurry $\mathrm{pH}$ (Yao et al., 2013). In brief, for each sample, three subsamples (5 g of fresh soil) were placed in $50 \mathrm{ml}$ falcon tubes containing $20 \mathrm{ml}$ 
of $1 \mathrm{mM}\left(\mathrm{NH}_{4}\right)_{2} \mathrm{SO}_{4}$. Potassium chlorate with a final concentration of $10 \mathrm{mg} \mathrm{ml}^{-1}$ was added to the tubes as an inhibitor of nitrite oxidation. The suspension was incubated in the dark at $25^{\circ} \mathrm{C}$ for $24 \mathrm{~h}$, and nitrite was extracted with $5 \mathrm{ml}$ of $2 \mathrm{M} \mathrm{KCl}$ and determined by a spectrophotometer at a wavelength of $540 \mathrm{~nm}$ with $\mathrm{N}$-(1-naphthyl) ethylenediamine dihydrochloride (He et al., 2007). PNR were calculated as the linear increase in nitrite concentrations during incubation.

\section{Quantitative PCR analysis of amoA gene}

$A O A$ and $A O B$ amoA gene abundances were quantified on a Corbett Rotor-Gene 6000 cycler (Qiagen, Doncaster, Vic., Australia) using the primers CrenamoA23f/CrenamoA616r (Tourna et al., 2008) and amoA-1F/amoA-2R (Rotthauwe et al., 1997) respectively. The $25 \mu$ reaction mixture contained $12.5 \mu \mathrm{l}$ SensiMix SYBR No-ROX reagent (Bioline, Sydney, NSW, Australia), $0.6 \mu$ l of each primer $(20 \mu \mathrm{M}), 1 \mu \mathrm{l}$ BSA $(20 \mathrm{mM})$ and $2 \mu \mathrm{l}$ of fivefold diluted template DNA (1-10 ng). Thermal-cycling conditions were as follows: $5 \mathrm{~min}$ initial denaturation at $95^{\circ} \mathrm{C}, 40$ cycles of $30 \mathrm{~s}$ at $95^{\circ} \mathrm{C}, 30 \mathrm{~s}$ at $53^{\circ} \mathrm{C}$ for $\mathrm{AOA}$ and $55^{\circ} \mathrm{C}$ for $\mathrm{AOB}, 1 \mathrm{~min}$ at $72^{\circ} \mathrm{C}$, followed by a plate read at $83^{\circ} \mathrm{C}$. Standard curves were generated using 10 -fold serial dilutions of plasmids containing correct inserts of $\mathrm{AOA}$ or $\mathrm{AOB}$ amoA genes. Melt curve analyses were conducted following each assay to verify the specificity of the amplification products, and the PCR efficiency for different assays ranged between $87 \%$ and $99 \%$.

\section{T-RFLP analysis}

The community structure of $\mathrm{AOA}$ and $\mathrm{AOB}$ was characterized by T-RFLP analysis of the amoA genes using the fluorescently labelled primers FAM-CrenamoA23f/ CrenamoA616r and VIC-amoA-1F/amoA-2R respectively. The PCR reactions in a $50 \mu \mathrm{l}$ mixture contained $2.5 \mathrm{U}$ of BioTaq DNA polymerase (Bioline), $0.5 \mu \mathrm{l}$ of each primer $(20 \mu \mathrm{M}), 1 \mu \mathrm{l}$ dNTP mix $(20 \mathrm{mM}), 5 \mu \mathrm{l} 10 \times \mathrm{NH}_{4}$ reaction buffer, $2 \mu \mathrm{l}$ BSA (20 mM), $2 \mu \mathrm{lgCl}_{2}$ solution $(50 \mathrm{mM})$ and $2 \mu \mathrm{l}$ of fivefold diluted template DNA (1-10 ng). Thermal cycling conditions for $\mathrm{AOA}$ and $\mathrm{AOB}$ were as follows: an initial denaturation of $5 \mathrm{~min}$ at $95^{\circ} \mathrm{C}, 35$ cycles of $30 \mathrm{~s}$ at $95^{\circ} \mathrm{C}, 30 \mathrm{~s}$ at $56^{\circ} \mathrm{C}, 1 \mathrm{~min}$ at $72^{\circ} \mathrm{C}$, followed by a final elongation of $72^{\circ} \mathrm{C}$ for $10 \mathrm{~min}$. The PCR products were purified using the Wizard SV Gel and PCR Clean-Up System (Promega, San Luis Obispo, CA, USA). The concentrations of PCR products were fluorometrically quantified using the Qubit dsDNA HS Assay Kit (Invitrogen, Carlsbad, CA, USA) according to manufacturer's instructions.

Restriction digests were performed in a $10 \mu \mathrm{l}$ mixture containing approximately $200 \mathrm{ng}$ purified PCR products, $5 \mathrm{U}$ of the restriction enzymes Rsal and $\mathrm{HpyCH} 4 \mathrm{~V}$ for AOA or Mspl (BioLabs, Sydney, NSW, Australia) for AOB, $0.1 \mu \mathrm{l} \mathrm{BSA}$ and $1 \mu \mathrm{l}$ of $10 \times$ NEBuffer. Digests were incubated at $37^{\circ} \mathrm{C}$ for $3 \mathrm{~h}$, followed by $95^{\circ} \mathrm{C}$ for $10 \mathrm{~min}$ to deactivate the restriction enzyme. TRFs were resolved on an ABI PRISM 3500 Genetic analyzer (Applied Biosystems, CA, USA). A GeneScan 600LIZ internal size standard (Applied Biosystems) was applied to each sample. T-RFLP profiles were analysed using a local southern size calling method (peaks between 50 and 650 bp in size) and a peak amplitude threshold setting of 50 , using
Genemapper version 4.0 (Applied Biosystems). TRFs with peak height comprising less than $2 \%$ of the total peak height were removed from downstream analysis, and peaks that differed by less than $1 \mathrm{bp}$ were binned into the same fragment. The relative fluorescence abundances of all TRFs were exported for further analysis.

\section{DNA-SIP incubation and SIP fractionation}

Soils taken from the field in November 2012 were immediately incubated in a SIP microcosm to identify the active autotrophic nitrifiers. For all the replicate samples, two sets of treatments in triplicate were employed in the incubation: $5 \%$ (v/v) ${ }^{12} \mathrm{CO}_{2}$ and $5 \%{ }^{13} \mathrm{CO}_{2}$ (99 atoms\%, Sigma-Aldrich, St Louis, MO, USA) was added to the headspace as described previously (Zhang et al., 2012). The SIP microcosms were performed in $160 \mathrm{ml}$ serum bottles containing $10 \mathrm{~g}$ of fresh soils and sealed with butyl rubber stoppers and aluminum caps. Aerobic conditions in the bottles were maintained by air refreshing every 3 days, then re-establishing the $\mathrm{CO}_{2}$ concentrations in the headspace. The water loss of soils was weekly replaced throughout the incubation. Microcosms were incubated at $28^{\circ} \mathrm{C}$ in the dark, and a destructive sampling was conducted after 30 days' incubation. Net nitrogen mineralization rates and net nitrification rates were estimated via the changes in concentrations of ammonium and nitrate during incubation (Gleeson et al., 2010).

Density gradient centrifugation was performed for triplicate SIP microcosms in $1.8 \mathrm{ml}$ seal tubes in a S120VT vertical rotor (Hitachi, Japan), subjected to isopycnic centrifugation at $140000 \mathrm{~g}_{\mathrm{av}}$ (70 000 r.p.m.) at $20^{\circ} \mathrm{C}$ for $36 \mathrm{~h}$. The extracted DNA $(\sim 1 \mu \mathrm{g})$ was loaded into the $\mathrm{CsCl}$ gradients with an initial average density of $1.72 \mathrm{~g} \mathrm{ml}^{-1}$ in the Trisethylenediaminetetraacetic acid (EDTA) buffer (pH 8.0, $10 \mathrm{mM}$ Tris- $\mathrm{HCl}, 1 \mathrm{mM}$ EDTA). A blank gradient without DNA was run each time to measure the expected buoyant densities. Centrifuged gradients were fractionated from bottom to top into 18 equal volumes $(\sim 100 \mu \mathrm{l}$ per fraction) by displacing the $\mathrm{CsCl}$ medium with sterile water, using a handmade fraction recovery system and a LSP02-1B syringe infusion pump (Longer Precision Pump, Baoding, China) at a flow rate of $100 \mu \mathrm{l} \mathrm{min}{ }^{-1}$. The buoyant density of each fraction was measured carefully by weighing the fractions from the blank gradient on a digital microbalance. Nucleic acids were subsequently pelleted from the $\mathrm{CsCl}$ solution by overnight precipitation in two volumes of $30 \%(\mathrm{w} / \mathrm{v})$ polyethylene glycol 6000 in $1.6 \mathrm{M} \mathrm{NaCl}$ at $4^{\circ} \mathrm{C}$, and the precipitated DNA was further washed using ice-cold $70 \%$ ethanol, then dissolved in $30 \mu \mathrm{l}$ of sterile water. The resulting DNAs were further checked by quantitative PCR to quantify the relative abundance of amoA gene copies in individual fractions. T-RFLP analysis was also performed for AOA amoA gene retrieved from both light and heavy SIP fractions.

\section{Cloning and sequencing}

To assign phylogenetic affiliation to specific TRFs, AOA and $\mathrm{AOB}$ amoA gene clone libraries were constructed. PCR amplifications for $\mathrm{AOA}$ and $\mathrm{AOB}$ were performed using the primers CrenamoA23f/CrenamoA616r and amoA-1F/ amoA-2R without fluorescent labelled. In total, two clone 
libraries were constructed for AOA from the light and heavy SIP fractions, respectively, and one clone library for $A O B$ from all the treatments. The pooled PCR products for each library were purified and ligated into the pGEM-T Easy vector (Promega, Madison, WI, USA), and the resultant ligation products were transformed into JM109 competent cells as per the manufacturer's instructions. Fifty clones were randomly selected for each library and subjected to T-RFLP analysis as described above. Clones sent for sequencing were chosen to cover most of the TRFs detected in this study, and detailed methodology for the selection criteria has been previously described (Singh et al., 2011). The obtained sequences were checked for chimeras and then aligned with reference sequences using MUSCLE implemented in MEGA 5.0 (Tamura et al., 2011). Phylogenetic analysis was conducted through neighbour-joining tree using Kimura 2-parameter distance with 1000 replicates to produce Bootstrap values within MEGA. Unique nucleotide sequences retrieved in this study have been deposited in GenBank under accession numbers KJ081252 to KJ081269 for AOA and KJ081270 to KJ081279 for $A O B$ respectively.

\section{Diagnostic amoA-based microarray analysis}

The patterns of community structures and phylogenetic distribution were further investigated by high-throughput microarray to characterize a broad range of ammonia oxidizers (Abell et al., 2012). Genomic DNA retrieved from the heavy SIP fractions was also used in microarray analysis to identify the metabolically 'active' AOA populations. The amplification of $A O A$ and $A O B$ amo $A$ genes were performed in the same way as described in T-RFLP analysis but using the modified primers CrenamoA23f/T7-CrenamoA616r and amoA-1F/T7-amoA-2R respectively. The T7 promoter site (5'TAATACGACTCACTATAG-3') was added to the $5^{\prime}$ end of the reverse primers, enabling T7 RNA polymerase-mediated in vitro transcription. Triplicate PCR assays (50 $\mu \mathrm{l}$ each) were performed for each sample, and the resultant PCR amplicons were pooled and purified using the Wizard SV Gel and PCR Clean-Up Kit. The concentrations of PCR products were qualified using the Qubit dsDNA HS Assay Kit and diluted to $50 \mathrm{ng}^{-1}$ as required by the microarray analysis. The detailed procedures of in vitro transcription, fragmentation, hybridization and scanning were described previously (Abell et al., 2012). Hybridization signal intensities for each probe were normalized to the positive control probes on the same array. The version of amoA microarray in this study contains 171 and 139 short oligonucleotide probes targeting $A O A$ and $A O B$ amo $A$ genes, respectively, and each probe is specific to a group of ammonia oxidizers.

\section{Statistical analyses}

The amoA gene copy numbers were log-transformed prior to statistical analysis to meet normality assumptions. One-way analysis of variance followed by Student-Newman-Keuls test was performed to compare the basic soil properties, $\mathrm{PNR}$, net nitrogen mineralization rates, net nitrification rates and the amoA gene copy numbers across different treatments in SPSS 20 (IBM, Armonk, NY, USA). Spearman's rank test was used to assess the correlations between the amoA gene copy numbers and PNR. $P<0.05$ was considered to be statistically significant. NMDS was used to visualize the Bray-Curtis dissimilarity matrices based on the relative abundances of $A O A$ and AOB TRFs. PerMANOVA was conducted to assess the significance of Bray-Curtis dissimilarity between different treatments by using the 'adonis' function in VEGAN package of R software (http://www.r-projext.org). The heat maps illustrating the microarray results of $A O A$ and $A O B$ were generated using the GPLOTS package in R. Redundancy analysis was performed to explore the effects of environmental variables on ammonia oxidizing groups represented by individual microarray probes within CANOCO 4.5 (Microcomputer Power, Ithaca, NY, USA). A multiple regression model was run to predict PNR with treatments, sampling seasons and all the examined soil parameters as explanatory variables in SPSS 20 (IBM Co., Armonk, NY, USA).

\section{Acknowledgements}

This work was financially supported by University of Western Sydney - Chinese Academy of Sciences bilateral agreement, Australian Research Council (DP130104841) and National Science Foundation of China (41025004). The site was established with support from the Australian Greenhouse Office Grant 0506/0085 and subsequently by the Commonwealth Department of Climate Change, with additional funding from the NSW Department of Environment and Climate Change (Grant T07 CAG/16). We gratefully acknowledge Luca Giaramida, Catarina Martins and Yong Zheng for their assistance during field sampling. Thanks to Barbara Drigo for great help in DNA stable isotope probing experiment.

\section{References}

Abell, G.C.J., Robert, S.S., Frampton, D.M.F., Volkman, J.K., Rizwi, F., Contos, J., and Bodrossy, L. (2012) Highthroughput analysis of ammonia oxidizer community composition via a novel, amoA-based functional gene array. PLOS ONE 7: e51542.

Austin, A.T., Yahdjian, L., Stark, J.M., Belnap, J., Porporato, A., Norton, U., et al. (2004) Water pulses and biogeochemical cycles in arid and semiarid ecosystems. Oecologia 141: 221-235.

Avrahami, S., and Bohannan, B.J.M. (2007) Response of Nitrosospira $s p$. Strain AF-like ammonia oxidizers to changes in temperature, soil moisture content, and fertilizer concentration. Appl Environ Microbiol 73: 1166-1173.

Barton, C.V.M., Ellsworth, D.S., Medlyn, B.E., Duursma, R.A., Tissue, D.T., Adams, M.A., et al. (2010) Whole-tree chambers for elevated atmospheric $\mathrm{CO}_{2}$ experimentation and tree scale flux measurements in south-eastern Australia: the Hawkesbury forest experiment. Agric For Meteorol 150: 941-951.

Booth, M.S., Stark, J.M., and Rastetter, E. (2005) Controls on nitrogen cycling in terrestrial ecosystems: a synthetic analysis of literature data. Ecol Monogr 75: 139-157.

Borken, W., and Matzner, E. (2009) Reappraisal of drying and wetting effects on $\mathrm{C}$ and $\mathrm{N}$ mineralization and fluxes in soils. Glob Change Biol 15: 808-824.

Brochier-Armanet, C., Boussau, B., Gribaldo, S., and Forterre, P. (2008) Mesophilic crenarchaeota: proposal for 
a third archaeal phylum, the thaumarchaeota. Nat Rev Microbiol 6: 245-252.

Chen, X.P., Zhu, Y.G., Xia, Y., Shen, J.P., and He, J.Z. (2008) Ammonia-oxidizing archaea: important players in paddy rhizosphere soil? Environ Microbiol 10: 19781987.

Chen, Y.L., Xu, Z.W., Hu, H.W., Hu, Y.J., Hao, Z.P., Jiang, Y., and Chen, B.D. (2013) Responses of ammonia-oxidizing bacteria and archaea to nitrogen fertilization and precipitation increment in a typical temperate steppe in Inner Mongolia. Appl Soil Ecol 68: 36-45.

Cray, J.A., Bell, A.N.W., Bhaganna, P., Mswaka, A.Y., Timson, D.J., and Hallsworth, J.E. (2013a) The biology of habitat dominance: can microbes behave as weeds? Microb Biotechnol 6: 453-492.

Cray, J.A., Russell, J.T., Timson, D.J., Singhal, R.S., and Hallsworth, J.E. (2013b) A universal measure of chaotropicity and kosmotropicity. Environ Microbiol 15: 287-296.

Dai, A. (2013) Increasing drought under global warming in observations and models. Nat Clim Chang 3: 52-58.

Delgado-Baquerizo, M., Maestre, F.T., Gallardo, A., Bowker, M.A., Wallenstein, M.D., Quero, J.L., et al. (2013) Decoupling of soil nutrient cycles as a function of aridity in global drylands. Nature 502: 672-676.

Di, H.J., Cameron, K.C., Shen, J.P., Winefield, C.S., O'Callaghan, M., Bowatte, S., and He, J.Z. (2009) Nitrification driven by bacteria and not archaea in nitrogen-rich grassland soils. Nat Geosci 2: 621-624.

Dore, M.H.I. (2005) Climate change and changes in global precipitation patterns: what do we know? Environ Int 31: 1167-1181.

Erguder, T.H., Boon, N., Wittebolle, L., Marzorati, M., and Verstraete, W. (2009) Environmental factors shaping the ecological niches of ammonia-oxidizing archaea. FEMS Microbiol Rev 33: 855-869.

Frew, A., Nielsen, U.N., Riegler, M., and Johnson, S.N. (2013) Doe eucalypt plantation management practices create understory reservoirs of scarab bittles pests in the soil. For Ecol Manage 306: 275-280.

Gleeson, D.B., Muller, C., Banerjee, S., Ma, W., Siciliano, S.D., and Murphy, D.V. (2010) Response of ammonia oxidizing archaea and bacteria to changing water filled pore space. Soil Biol Biochem 42: 1888-1891.

Gubry-Rangin, C., Hai, B., Quince, C., Engel, M., Thomson, B.C., James, P., et al. (2011) Niche specialization of terrestrial archaeal ammonia oxidizers. Proc Natl Acad Sci USA 108: 21206-21211.

Hallsworth, J.E., Yakimov, M.M., Golyshin, P.N., Gillion, J.L.M., D'Auria, G., Alves, F.L., et al. (2007) Limits of life in $\mathrm{MgCl} 2$-containing environments; chaotropicity defines the window. Environ Microbiol 9: 803-813.

He, J.Z., Shen, J.P., Zhang, L.M., Zhu, Y.G., Zheng, Y.M., Xu, M.G., and Di, H.J. (2007) Quantitative analyses of the abundance and composition of ammonia-oxidizing bacteria and ammonia-oxidizing archaea of a Chinese upland red soil under long-term fertilization practices. Environ Microbiol 9: 2364-2374.

He, J.Z., Hu, H.W., and Zhang, L.M. (2012) Current insights into the autotrophic thaumarchaeal ammonia oxidation in acidic soils. Soil Biol Biochem 55: 146-154.
Houghton, J.T., Ding, Y., Griggs, D.J., Noguer, M., van der Linden, P.J., Dai, X., et al. (2001) Climate Change 2001: The Scientific Basis. Cambridge, UK: Cambridge University Press.

Hu, H.W., Zhang, L.M., Dai, Y., Di, H.J., and He, J.Z. (2013) $\mathrm{pH}$-dependent distribution of soil ammonia oxidizers across a large geographical scale as revealed by high-throughput pyrosequencing. J Soils Sediments 13: 1439-1449.

Hu, H.W., Xu, Z.H., and He, J.Z. (2014) Ammonia oxidizing archaea play a predominant role in acid soil nitrification. Adv Agron 125: 261-303.

Jia, Z.J., and Conrad, R. (2009) Bacteria rather than archaea dominate microbial ammonia oxidation in an agricultural soil. Environ Microbiol 11: 1658-1671.

Kurola, J., Salkinoja-Salonen, M., Aarnio, T., Hultman, J., and Romantschuk, M. (2005) Activity, diversity and population size of ammonia-oxidizing bacteria in oil-contaminated landfarming soil. FEMS Microbiol Lett 250: 33-38.

Lauber, C.L., Strickland, M.S., Bradford, M.A., and Fierer, N. (2008) The influence of soil properties on the structure of bacterial and fungal communities across land-use types. Soil Biol Biochem 40: 2407-2415.

Lennon, J.T., and Jones, S.E. (2011) Microbial seed banks: the ecological and evolutionary implications of dormancy. Nat Rev Microbiol 9: 119-130.

Manzoni, S., Schimel, J.P., and Porrorato, A. (2012) Responses of soil microbial communities to water stress: results from a meta-analysis. Ecology 93: 930-938.

Millennium Ecosystem Assessment (2005) Drylands systems. In Ecosystems and Human Wellbeing: Current State and Trends. Hassan, R., Scholes, R., and Ash, N. (eds). Washington, DC, USA: Island Press, pp. 625655.

Mußmann, M., Brito, I., Pitcher, A., Damste, J.S.S., Hatzenpichler, R., Richter, A., et al. (2011) Thaumarchaeotes abundant in refinery nitrifying sludges express amoA but are not obligate autotrophic ammonia oxidizers. Proc Natl Acad Sci USA 108: 16771-16776.

Myers, B.J., Theiveyanathan, S., O'Brien, N.D., and Bond, W.J. (1996) Growth and water use of Eucalyptus grandis and Pinus radiata plantations irrigated with effluent. Tree Physiol 16: 211-219.

Nazaries, L., Tate, K.R., Ross, D.J., Singh, J., Dando, J., Baggs, E.M., et al. (2011) Response of methanotroph communities to afforestation and reforestation in New Zealand. ISME J 5: 1832-1836.

Placella, S.A., and Firestone, M.K. (2013) Transcriptional response of nitrifying communities to wetting of dry soil. Appl Environ Microbiol 79: 3294-3302.

Pointing, S.B., Chan, Y., Lacap, D.C., Lau, M.C., Jurgens, J.A., and Farrel, R.L. (2009) Highly specialized microbial diversity in hyper-arid polar desert. Proc Natl Acad Sci USA 106: 19964-19969.

Pratscher, J., Dumont, M.G., and Conrad, R. (2011) Ammonia oxidation coupled to $\mathrm{CO}_{2}$ fixation by archaea and bacteria in an agricultural soil. Proc Natl Acad Sci USA 108: 4170-4175.

Prosser, J.I., and Nicol, G.W. (2012) Archaeal and bacterial ammonia oxidizers in soil: the quest for niche specialization and differentiation. Trends Microbiol 20: 523-531.

Purkhold, U., Pommerening-Roser, A., Juretschko, S., 
Schmid, M.C., Koops, H.P., and Wagner, M. (2000) Phylogeny of all recognized species of ammonia oxidizers based on comparative 16S rRNA and amoA sequence analysis: implications for molecular diversity surveys. Appl Environ Microbiol 66: 5368-5382.

Rotthauwe, J.H., Witzel, K.P., and Liesack, W. (1997) The ammonia monooxygenase structural gene amo $A$ as a functional marker: molecular fine-scale analysis of natural ammonia-oxidizing populations. Appl Environ Microbiol 63: 4704-4712.

Schaeffer, S.M., Sharp, E., Schimel, J.P., and Welker, J.M. (2013) Soil-plant N processes in a high Arctic ecosystems, NW Greenland are altered by long-term experimental warming and higher rainfall. Glob Change Biol 19: 35293539 .

Schafer, A.N., Snape, I., and Siciliano, S.D. (2007) Soil biogeochemical toxicity end points for sub-Antarctic islands contaminated with petroleum hydrocarbons. Environ Toxicol Chem 26: 890-897.

Schauss, K., Focks, A., Leininger, S., Kotzerke, A., Heuer, H., Thiele-Bruhn, S., et al. (2009) Dynamics and functional relevance of ammonia-oxidizing archaea in two agricultural soils. Environ Microbiol 11: 446-456.

Schimel, D.S. (2010) Drylands in the earth system. Science 327: 418-419.

Schimel, J., Balser, T.C., and Wallenstein, M. (2007) Microbial stress-response physiology and its implications for ecosystem function. Ecology 88: 1386-1394.

Shen, J.P., Zhang, L.M., Zhu, Y.G., Zhang, J.B., and He, J.Z. (2008) Abundance and composition of ammoniaoxidizing bacteria and ammonia-oxidizing archaea communities of an alkaline sandy loam. Environ Microbiol 10: 1601-1611.

Shen, J.P., Cao, P., Hu, H.W., and He, J.Z. (2013) Differential response of archaeal groups to land use change in an acidic red soil. Sci Total Environ 461-462: 742-749.

Singh, B.K., Bardgett, R.D., Smith, P., and Reay, D. (2010) Microorganisms and climate change: feedbacks and mitigation options. Nat Rev Microbiol 8: 779-790.

Singh, B.K., Tate, K., Thomas, N., Ross, D., and Singh, J. (2011) Different effect of afforestation on nitrogen-fixing and denitrifying communities and potential implications for nitrogen cycling. Soil Biol Biochem 43: 1426-1433.

Spang, A., Poehlein, A., Offre, P., Zumbragel, S., Haider, S., Rychlik, N., et al. (2012) The genome of the ammoniaoxidizing Candidatus Nitrososphaera gargensis: insights into metabolic versatility and environmental adaptations. Environ Microbiol 14: 3122-3145.

Stark, J.M., and Firestone, M.K. (1995) Mechanisms for soil moisture effects on activity of nitrifying bacteria. Appl Environ Microbiol 61: 218-221.

Stopnišek, N., Gubry-Rangin, C., Levicnik-Höfferle, S., Nicol, G.W., Mandic-Mulec, I., and Prosser, J.I. (2010) Thaumarchaeal ammonia oxidation in an acidic forest peat soil is not influenced by ammonium amendment. Appl Environ Microbiol 76: 7626-7634.

Tamura, K., Peterson, D., Peterson, N., Stecher, G., Nei, M., and Kumar, S. (2011) MEGA5: molecular evolutionary genetics analysis using maximum likelihood, evolutionary distance, and maximum parsimony methods. Mol Biol Evol 28: $2731-2739$.
Tourna, M., Freitag, T.E., Nicol, G.W., and Prosser, J.I. (2008) Growth, activity and temperature responses of ammoniaoxidizing archaea and bacteria in soil microcosms. Environ Microbiol 10: 1357-1364.

Verhamme, D.T., Prosser, J.I., and Nicol, G.W. (2011) Ammonia concentration determines differential growth of ammonia-oxidizing archaea and bacteria in soil microcosms. ISME J 5: 1067-1071.

Walker, C.B., de la Torre, J.R., Klotz, M.G., Urakawa, H., Pinel, N., Arp, D.J., et al. (2010) Nitrosopumilus maritimus genome reveals unique mechanisms for nitrification and autotrophy in globally distributed marine Crenarchaea. Proc Natl Acad Sci USA 107: 8818-8823.

Williams, J.P., and Hallsworth, J.E. (2009) Limits of life in hostile environments: no limits to biosphere function? Environ Microbiol 11: 3292-3308.

Wrage, N., Velthof, G.L., van Beusichem, M.L., and Oenema, O. (2001) Role of nitrifier denitrification in the production of nitrous oxide. Soil Biol Biochem 31: 1723-1732.

Xia, W.W., Zhang, C.X., Zeng, X.W., Feng, Y.Z., Weng, J.H., Lin, X.G., et al. (2011) Autotrophic growth of nitrifying community in an agricultural soil. ISME J 5: 1226-1236.

Yao, H.Y., Campbell, C.D., Chapman, S.J., Freitag, T.E., Nicol, G.W., and Singh, B.K. (2013) Multi-factorial drivers of ammonia oxidizer communities: evidence from a national soil survey. Environ Microbiol 15: 2545-2556.

Ying, J.Y., Zhang, L.M., and He, J.Z. (2010) Putative ammonia-oxidizing bacteria and archaea in an acidic red soil with different land utilization patterns. Environ Microbiol Rep 2: 304-312.

Zhang, L.M., Hu, H.W., Shen, J.P., and He, J.Z. (2012) Ammonia-oxidizing archaea have more important role than ammonia-oxidizing bacteria in ammonia oxidation of strongly acidic soils. ISME J 6: 1032-1045.

\section{Supporting information}

Additional Supporting Information may be found in the online version of this article at the publisher's web-site:

Fig. S1. Phylogenetic analysis of the AOA amoA gene sequences retrieved from ${ }^{13} \mathrm{C}-\mathrm{CO}_{2}$-DNA-SIP light and heavy fractions of all the treatments. The sequences identified for TRFs digested by the Rsal and HpyCH4V enzymes are highlighted in red and blue respectively. The scale bar represents $5 \%$ nucleic acid sequence divergence, and bootstrap values (>50\%) are indicated at branch points.

Fig. S2. Terminal restriction fragment length polymorphism (T-RFLP) fingerprints of the AOA amoA gene fragments digested using the $\mathrm{HpyCH} 4 \mathrm{~V}$ enzyme (a) across different treatments (G, grassland; C, control; F, fertilization; I, irrigation; IF, irrigation + fertilization; and $S$ and $W$ denote samples collected form spring and winter respectively). Error bars represent standard errors $(n=4)$. Non-metric multidimensional scaling (NMDS) ordinations derived from the Bray-Curtis dissimilarity matrices were based on the relative abundance of AOA TRFs. The stress value for the NMDS plot was lower than 0.12 indicating that these data were wellrepresented by the two-dimensional ordinations.

Fig. S3. Phylogenetic analysis of the AOB amoA gene sequences retrieved from the genomic DNA of all the 
treatments. The sequences identified for the TRFs digested by the Mspl enzyme are highlighted in red. The scale bar represents $2 \%$ nucleic acid sequence divergence, and bootstrap values (> 50\%) are indicated at branch points.

Fig. S4. Ordination triplot of redundancy analysis on total AOA community determined by microarray, using $\mathrm{pH}$, soil moisture, nitrate, ammonia, total carbon and total nitrogen as explanatory variables. The red arrows indicate the vectors of the explanatory variables, and the grey arrows are the vectors of the AOA microarray probes representing each $A O A$ groups.

Fig. S5. Ordination triplot of redundancy analysis on total AOB community determined by microarray, using $\mathrm{pH}$, soil moisture, nitrate, ammonia, total carbon and total nitrogen as explanatory variables. The red arrows indicate the vectors of the explanatory variables, and the grey arrows are the vectors of the $A O B$ microarray probes representing each AOB groups. 